\title{
E-kitaplar için Koleksiyon Geliştirmede Farklı Sağlama Modellerinin Etkisi $^{*}$
}

\section{The Effects of Different Acquisition Models on Collection Development for E-books}

\author{
Damla Yılmaz ${ }^{* *}$ ve Yurdagül Ünal***
}

\section{$\ddot{\boldsymbol{O}} \boldsymbol{z}$}

E-kitaplar eğitim ve araştırma faaliyetlerini desteklemede kütüphane koleksiyonu içerisinde önemli bir yere sahiptir. Kütüphanelerin bütçelerini etkin bir şekilde kullanarak doğru ve dengeli bir koleksiyon oluşturabilmesi için farklı sağlama modellerini takip etmeleri ve değerlendirmeleri gerekmektedir. Tedarikçiler tarafindan sunulan içeriğe hangi şartlarda ve nasıl erişim să̆lanacağını gösteren farklı e-kitap să̆lama modelleri bulunmakta ve bu modeller ekonomik şartlar ve teknolojik gelişmeler nedeniyle sürekli değişmektedir. Bu çalışmanın amacı; să̆lama modeli tercihinin toplam harcama maliyetlerini nasıl etkilediğini, model tercihinin disipline göre değişip değişmediğini, en uygun maliyete ve birim kullanım maliyetine sahip săglama modellerinin hangisi olduğunu araştırmaktır. Çalışma kapsamında; Hacettepe Üniversitesi Kütüphaneleri için gerçek kullanım verilerine dayanarak yayıncı ve derleyici firma tarafindan sunulan e-kitap sağlama modelleri test edilmiş ve geliştirilen senaryolarla maliyet ve konu analizi yapılmıstır. Yayınc tarafindan sunulan EBA (Evidence Based Acquisition) modelinde birim kullanım maliyetinin 1,18€ olduğu ve bu modelin tercih edilmesi durumunda garantili ve daha düşük harcamaların yapılabileceği ortaya çıkmıştır. Derleyici firmanın sunduğu modeller arasında ise en düşük birim kullanım maliyeti 13,75\$ ile STL'li (STL - Short Term Loan) DDA (Demand Driven Acquisition) modelinde görülmüştür. En fazla kullanılan başlıkların otomatik satın alınmasına izin veren bu modelin kütüphane için ekonomik bir seçenek olacă̆ ortaya çıkmıştır. E-kitap kullanım sıklılarının disipline göre farklılık gösterdiği, ödenen toplam maliyet ve kullanım sayısına bağlı olarak birim kullanım maliyetlerinin değiştiği sonucuna ulaşılmıştır. Disipline göre sağlama modellerinin tercihinde kullanım, bütçe ve tedarikçi koşullarının etkili olduğu görülmüştür. E-kitap sağlama modellerinin karşılaştırmalı maliyet analizinin yapıldığı bu araştırmanın sonuçları koleksiyon geliştirme ve yönetiminde kullanılmal, kullanım verilerinin analizi ile en uygun ve en ekonomik sağlama modelleri dĕ̆erlendirilerek bütçelerin daha etkin kullanılması sağlanmalıdır.

Anahtar Sözcükler: E-kitap; koleksiyon geliştirme; sağlama modelleri; DDA modeli; EBA modeli; talep odaklı să̆lama; kanıta dayalı să̆lama.

\footnotetext{
* Bu makale Hacettepe Üniversitesi Bilgi ve Belge Yönetimi Bölümünde hazırlanan "E-kitap Sağlama Modellerinin Karşılaştırmalı Analizi: Hacettepe Üniversitesi Örneği” başlıklı yüksek lisans tezine dayanılarak hazırlanmıştır.

** Kütüphaneci, Hacettepe Üniversitesi Kütüphaneleri. E-posta: dyilmaz@ hacettepe.edu.tr Librarian, Hacettepe University Libraries, Turkey.

*** Doç. Dr. Hacettepe Üniversitesi Bilgi ve Belge Yönetimi Bölümü. E-posta: yurdagul@ hacettepe.edu.tr Associate Prof., Hacettepe University Department of Information Management, Turkey.
} 


\section{Abstract}

E-books have an important place in library collections in supporting education and research activities. Libraries need to follow and evaluate different acquisition models which vary by supplier, in order to create an effective and balanced collection by using their budgets efficiently. There are different e-book acquisition models that show under which conditions content by suppliers may be accessed. These models are constantly changing due to economic conditions and technological developments. The purpose of this study is to investigate how the choice of acquisition model affects total library expenditures, whether the choice of model changes according to the discipline, and which are the most cost-effective unit-use procurement models. In this study, based on real usage data from Hacettepe University Libraries, e-book acquisition models offered by the publisher and aggregator were tested and, then cost and subject analyses were made with the developed scenarios. Among the models offered by the publisher a unit usage cost of $1.18 €$ was seen in the EBA (Evidence Based Acquisition) model. If this model was preferred there would be guaranteed lower expenses. Among the models offered by the aggregator, the lowest unit usage cost (\$13.75) was seen in the DDA (Demand Driven Acquisition) model with STL (STL - Short Term Loan). With the use of STL, the most used titles were purchased automatically, and the DDA model with STL became an economical option for the library. It was concluded that the frequency of e-book usage varies according to discipline, and unit usage costs vary depending on the total cost paid and the number of uses. The budget of the library, the supplier conditions, and usage data affect the preference of acquisition models according to discipline. The results of this research, in which a comparative cost analysis of e-book acquisition models was performed, should be used in collection development and management. Usage data should be analyzed, and the most appropriate and economic acquisition models should be determined, in order for budgets to be used more effectively.

Keywords: E-book, collection development; acquisition models; DDA model; EBA model; demand driven acquisition; evidence based acquisition.

\section{Giriş}

Bilgi ve iletişim teknolojilerindeki hızlı gelişim yayıncılık sektöründeki yenilikleri de beraberinde getirmiştir. Elektronik yayıncılık kavramının oluşması ile birlikte kütüphaneler elektronik kitap (e-kitap) koleksiyonlarını oluşturma ve geliştirme yoluna gitmişlerdir. Ancak e-kitapların akademik kütüphanelerde kullanım ve çeşitliliğinin artması yönetim süreci ile ilgili birtakım sorunları da beraberinde getirmiştir. Kullanıcı ihtiyacını karşılayan ve bütçenin verimli kullanıldığı bir e-kitap koleksiyonu geliştirebilmek, e-kitapların yönetimi ile ilgili sorunlara çözüm bulabilmek için ilgili süreçlerin incelenmesi gerekmektedir. Literatürde e-kitap yönetim süreçlerini konu alan pek çok çalışma bulunmaktadır (Armstrong ve Lonsdale, 2005; Johnson, 2013; Maceviciute, Borg, Kuzminiene ve Konrad, 2014; Vasileiou, Hartley ve Rowley, 2012; Vasileiou, Rowley ve Hartley, 2012).

E-kitap yönetim sürecinde üzerinde önemle durulması ve doğru karar verilmesi gereken konuların başında sağlama modelleri gelmektedir. İçeriğe hangi şartlarda ve nasıl erişileceğini belirleyen sağlama modelleri ekonomik şartlar ve teknolojik gelişmeler nedeniyle sürekli değişmektedir. Özellikle e-kitapların çeşitliliği tedarikçiye göre farklılık gösteren sağlama modellerinin çeşitliliği (Maceviciute ve diğerleri, 2014; McKiel, 2007; Johnson, 2013) ile 
birleştiğinde kurumların bu modellere karar vermesinin pek de kolay olmadığını söylemek mümkündür. Tedarikçilerin talep edilen sağlama modelinde istenen başlıkların tamamını karşılaması başka bir ifadeyle tek bir sağlama modelinin tüm kütüphaneler için en uygun şartları sunması veya tüm yayıncılar tarafindan benimsenmesi mümkün değildir (Morris ve Sibert, 2011, s. 98). Kullanıcı ihtiyaçlarını karşılayabilmede en etkili yolun hangisi olduğuna karar verilmesi akademik kütüphaneler açısından oldukça önemli bir konudur (Bucknell, 2012, s. 59). Bu kapsamda kurumların sağlama modellerini çok iyi analiz etmesi ve lisans sözleşmeleriyle birlikte koleksiyon geliştirme politikalarını destekleyebilecek modelleri seçmesi gerekmektedir.

\section{E-Kitap Sağlama Modelleri}

Yalnızca kendi başlıklarını doğrudan kütüphanelere sunan yayıncılar, yayıncıların başlıklarını toplayarak bunları tek bir platformda sunan derleyiciler ve e-kaynak bulma, satın alma gibi konularda kütüphanelere yardımcı olan satıcılar e-kitaplar için çeşitli sağlama modelleri sunarken kütüphaneler de bu modellerden en uygun fiyatlarla yararlanmaya çalışmaktadır. Ekitap sağlama modellerini satın alma (sürekli erişim), abonelik (sadece erişim), kiralama (kullanım başına veya görüntüleme başına ödeme), talep odaklı sağlama (Demand Driven Acquisition- DDA) kanıta dayalı sağlama (Evidence Based Acquisition- EBA) ve onay planlarına bağlı sağlama başlıkları altında toplamak mümkündür.

Satın alma (sürekli erişim) bireysel başlık veya e-kitap koleksiyonlarının satıcı, yayıncı veya derleyiciden kalıcı olarak temin edilmesidir (Vasileiou, Hartley ve diğerleri, 2012, s. 25). E-kitap sağlama için en çok tercih edilen bu model (Anson ve Connell, 2009; McKiel, 2007; Newman, 2010) yayıncı ve erişim türüne bağlı olarak abonelik modeline göre daha pahalıdır (Grigson, 2011, s. 27). Ayrıca paket içindeki başlıklara müdahale edilememesi az kullanılacak ya da hiç kullanılmayacak materyallerin kütüphane koleksiyonuna dâhil edilmesine neden olabilmektedir (Ashcroft, 2011; Grigson, 2011; Soules, 2009). Ancak başlangıçta pahalı olmasına rağmen kitabın sonraki yıllarda da kullanılacağı varsayımı modelin uzun vadede daha fazla avantaj sağladığını ortaya koymaktadır.

Abonelik modeli sürekli erişim hakkı olmadan bir koleksiyona veya konu alanına erişim için genellikle bir yıllık ödemenin yapılmasıdır (Vasileiou, Hartley ve diğerleri, 2012, s. 25; Maceviciute ve diğerleri, 2014). Fiyatlar satın alma modeline göre daha düşüktür ve platform ücretleri fiyatlandırmaya dâhil edilmiştir (Grigson, 2011, s. 28). Ancak bir abonelik başlangıçta satın alma fiyatından daha düşük maliyetli olsa da abonelik yenileme dönemindeki yıllık maliyetler genellikle bunu daha pahalı bir seçenek haline getirebilmektedir (Lalla, 2012, s. 25). İçerik genellikle satıcı veya yayıncı tarafından belirlenmekte, kütüphanelere başlık listelerini şekillendirme seçeneği sunulmamaktadır (Maceviciute ve diğerleri, 2014; Morris ve Sibert, 2011, s. 99). İçeriğin kısa bir süre için kullanılması veya talebin kısa ömürlü olması durumunda bu modelle sağlanan geçici erişimin daha ekonomik olduğu söylenebilir.

Kütüphaneler arası ödünç vermeye alternatif olarak değerlendirilen kiralama modelinde ise bireysel başlıklara sınırlı bir süre için erişim sağlanmaktadır (Vasileiou, Hartley ve diğerleri, 2012, s. 25). Kullanım başına veya görüntüleme başına ödeme olarak da adlandırılan modelde kullanıcı tedarikçinin web sitesinde bulunan tüm e-kitapları tarayabilmektedir. Yalnızca kullanıcının talep ettiği kaynaklara ödeme yapılması daha ekonomik olmakla birlikte, kaynağın 
sadece bir kullanıcı tarafından sınırlı bir süre boyunca kullanılması, kütüphanelerin koleksiyonlarına herhangi bir içerik eklemeden, kendilerini büyük miktarlarda harcama yaparken bulmasına da neden olabilmektedir (Grigson, 2011, s. 29).

Kullanıcı odakl sağlama (Patron Driven Acquisition-PDA) veya talep odakl sağlama (Demand Driven Acquisition-DDA) olarak bilinen modelde önceden belirlenen e-kitaplar keşif sistemine yüklenmekte ve başlık belli bir sayıda tıklandığında, okunduğunda veya indirildiğinde kütüphane tarafından satın alınmaktadır (Grigson, 2011, s. 29; Johnson, 2014, s. 150; Kahn ve Underwood, 2013, s. 13). Model; belirli sayıda kullanımın gerçekleşmesi ardından otomatik satın alma ve/veya kullanıcının kısa bir süre için başlığa erişmesine izin veren belirli sayıda kısa vadeli ödünç (Short Term Loan-STL) işleminden sonra otomatik satın alma şeklinde ikiye ayrılmaktadır. Çoğu DDA modelinde, e-kitapların nasıl tetikleneceği (kullanıcı talebi ile satın alma için gerekli koşulların oluşması) sağlayıcıya göre değişmekle birlikte yaygın bir tetikleme eşiği, kitabın ilk 10 sayfası içinde 10 dakika arka arkaya kullanımda veya bir yazdırma, kopyalama ya da bir indirmede gerçekleşmektedir. Ayrıca 1010-1-1-1 paradigması olarak da bilinen bu koşullardan herhangi biri karşılandığında otomatik satın alma ya da STL kullanımı gerçekleşmektedir (Zhang, Downey, Urbano ve Klingler, 2015, s. 85). DDA modelinde kullanıcıların başlık seçmesine izin verilmesi birkaç kullanıcının çıkarlarını yansıtan dengesiz bir koleksiyonun oluşmasıyla sonuçlanabilmektedir. Hodges, Preston ve Hamilton (2010) kullanıcıların acil ihtiyaçlarına yönelik yapılan satın alımlarla zaman içinde akademik koleksiyonların yapısının değişebileceğine vurgu yapmaktadırlar. Bu riskin kullanıcılara seçim için sunulan başlıkların sayısının sınırlandırılması ya da talep edilen isteklerin sayısının azaltılması yoluyla giderilmesi mümkündür. Shen ve diğerleri de (2011, s. 217) başlıkların fiyatına sınırlama getirerek ve bazı kısıtlamalarla birlikte DDA modellerinin daha dikkatli bir şekilde uygulanması gerektiğini belirtmişlerdir.

Kanıta dayalı sağlama (Evidence Based Acquisition-EBA) modelinde bir yıl boyunca kullanıma sunulacak yayıncı koleksiyonları kütüphaneler tarafından seçilmekte ve koleksiyona abone olmanın maliyetinden daha yüksek ancak satın alma maliyetinden daha düşük bir ücret ödenmektedir. Kararlaştırılan sürenin sonunda kütüphanelerin önceden yaptıkları ödeme miktarı tutarında e-kitap satın alınmaktadır. Kullanım istatistiklerine bakarak satın alma kararını kütüphaneler verdiği için modelin tam anlamıyla kullanıcı odaklı olduğunu söylemek mümkün değildir. Ayrıca tek bir yayıncıya ait koleksiyondan garantili bir harcama yapma zorunluluğu da bulunmaktadır (E-BASS25, 2013). Abonelik bedelinden daha fazla ücret ödendiği için modelin bütçe kısıtlaması olan kütüphaneler açısından çok da uygun olmadığ1 söylenebilir. Ödenmesi gereken toplam miktar çok yüksekse kütüphane az veya hiç kullanılmamış başlıkları satın almak durumunda kalabilmektedir. Ayrıca erişim sağlanan koleksiyonun aynı olması durumunda ilk yıl en çok talep edilen başlıkların kullanılması ve anlaşmaya devam edilmesi durumunda ise ikinci yıla daha az kullanılan başlıkların kalması muhtemeldir. $\mathrm{Bu}$, kütüphanelerin koleksiyona yeni başlıkların eklenmesi ve modelin uygulanmasına devam edilecekse ikinci ve sonraki yıllar için daha az maliyetle anlaşmaların müzakere edilmesini gerektirmektedir. Böylece zamanla birçok başlık satın alınabilecek ve kütüphaneler çok az veya hiç kullanımı olmayan başlıkları satın almak durumunda kalmayacaktır (Machovec, 2013, s. 395).

Basılı kaynaklar için kullanılan geleneksel onay planları e-kitaplar için de sunulmaktadır. Konu, yayınc1, fiyat vb. durumlar dikkate alınarak kütüphanenin profili ve tercihlerine uygun 
oluşturulan onay planlarına bağlı sağlama modeli ile elektronik veya basılı alımların otomatik yapılması mümkündür (Doucette ve Lewontin, 2012, s. 57). Ancak kitap elektronik tercih edilirse erişiminin açılması ya da tam tersi bir istekte, basılı kitap mevcut olana kadar beklenmesi durumunda bir formatı diğerine tercih etmenin mümkün olduğu bir sistemin kurulmas1 gerekebilir (Morris ve Sibert, 2011, s. 113).

\section{Önceki Çalıșmalar}

Literatürde e-kitap sağlama modellerini değerlendiren ve bu modellere yönelik yayıncı ve konu analizlerinin yapıldığ

Westminster Üniversitesi Kütüphanesinin abonelikle eriştiği ve bireysel olarak seçtiği başlıkların değerlendirildiği bir çalışmada az sayıda başlığın aslında ihtiyacın büyük bir kısmını karşıladığı ve eş zamanlı tek kullanıcı seçeneği yerine yıllık kullanım limitine dayalı modelin daha iyi bir sonuç sunduğu görülmüş̧ür. Bu değerlendirmeler üniversite için en uygun maliyetli sağlama modelinin belirlenmesinde yardımcı olmuştur (Grigson, 2009). Brigham Young Üniversitesinde de benzer bir sonuçla karşılaşılmış ve kullanıcıların PDA modelinde sadece araştırma ve ilgi alanlarına yönelik kitaplara yöneldikleri ve kitapların belirli bir kısmının kullanıldığg sonucuna ulaşılmıştır. İyi bir deneyim olsa da PDA'nın kütüphane koleksiyonunu doğrudan yansıtmadığı ve listeleri oluşturmada konu kütüphanecilerine ihtiyaç duyulduğu belirtilmiştir (Schroeder, Wright ve Murdoch, 2010).

Kullanıcıların seçtiği başlıklar ile konu kütüphanecilerinin seçtiği başlıkların karşılaştırmasının yapıldığı bir çalışmada ortak seçim sayısının düşük çıktığı ve seçilen ekitapların ortalama maliyetinin birbirine yakın olduğu görülmüştür. Ortak seçim sayısının düşük olması kullanıcıların ve kütüphanecilerin farklı bakış açısına sahip olmasıyla açıklanmıştır. E-kitap kullanımının disiplinlere göre farklılık göstermesi nedeniyle alımlarda tüm disiplinler için eşit fon ayırmak yerine bütçelerin yeniden gözden geçirilmesi gerektiği ortaya çıkmıştır. Hem kullanıcı odaklı hem de geleneksel kütüphaneci seçimlerindeki bazı boşlukların doldurulmasında bu çalışmaların kütüphanelere yol gösterici olabileceği belirtilmiştir (Shen ve diğerleri, 2011). Purdue Üniversitesi Kütüphanelerinde PDA modeliyle sağlanan e-kitaplar ile kütüphaneciler tarafından seçilen e-kitapların karşılaştırmalı analizi yapılmıştır. PDA modelinde STL'nin kullanılmasıyla maliyet artmış olsa da otomatik satın alımı tetikleyen başlıklar en fazla kullanılan başlıklar olmuş ve model kısa veya orta vadede kullanıcı ihtiyaçlarını karşılamıştır. Kütüphaneciler tarafından seçilen başlıklarda ise hangi başlıkların kullanılacağını tahmin etmenin çok zor olduğu görülmüştür. Kütüphaneciler tarafından seçilen başlıkların PDA modeli ile sağlanması durumunda bazı kitapların herhangi bir maliyetinin olmayacağı ve hatta tasarruf sağlanacağı sonucuna ulaşılmıştır (Ward ve Richardson, 2016).

Liverpool Üniversitesi (UoL) Kütüphanesi için alternatif satın alma stratejileri araştırılmıştır. Kütüphanenin abone olduğu koleksiyon için görüntülenen sayfa başına maliyet abonelik dönemine bağlı olarak değişim göstermiştir. Tek seferlik bir satın almada ise ödeme bir kez yapıldığı için maliyetin yıldan yıla azaldığı sonucuna ulaşılmıştır. Yıl boyunca düzenli olarak satın alınan e-kitaplar için yapılan harcama miktarı ve kullanımın başladığı zaman dikkate alınmak şartıyla maliyet azalmıştır. UoL Kütüphanesinde e-kitapların kullanım istatistiklerine dayanarak PDA modelinin kullanıldığı varsayıldığında, modelin koleksiyonun 
fiyatını aşacağı ve çok kullanılan kitaplarda PDA modelini uygulamanın mantıklı olmadığ1 belirtilmiştir (Bucknell, 2012).

Kent State Üniversitesi Kütüphanelerinde STL olmadan DDA modeli araştırılmış ve 1010-1-1-1 tetikleyici formülü kullanılmıştır. Bu durumda kütüphane kataloğuna yüklenen kayıtların \%87'sinin kullanılmadığı, kullanılan \%13 oranındaki e-kitabın ise sadece \%5'inin tetiklenerek satın alındığ 1 ve geri kalan \%8'in ise tetik eşiğinin altında kullanımının olduğu görülmüştür. Uygulanan senaryolar herhangi bir STL olmadan mevcut DDA uygulamasına devam edilmesi durumunda daha düşük bir maliyet elde edildiğini göstermiştir. STL'nin uygulandığı diğer senaryolarda ise bir günlük STL'lerde \%21, bir haftalık STL'lerde \%33 oranında ek masraf olduğu ve her iki senaryoda da edinilen e-kitaplar için daha yüksek bir satın alma bedelinin ortaya çıktığı görülmüştür. Çalışmada akademik kütüphaneler için STL seçeneğinin ekonomik olmadığı sonucuna ulaşılmıştır (Zhang ve diğerleri, 2015).

Brigham Young Üniversitesindeki farklı e-kitap sağlama stratejilerinin onay planı üzerinde nasıl bir etkisi olduğu ve harcamaların bu durumdan nasıl etkilendiği araştırılmıştır. Uygulanan farklı modellerin her biri onay planını etkileyerek satın alınan kitapların sayısını ve maliyetini azaltmıştır (Schroeder ve Boughan, 2017). Swinburne Teknoloji Üniversitesinde mümkün olduğunca çok sayıda e-kitabı koleksiyona katabilmek, koleksiyonun kullanımını sağlamak ve harcamaları sürdürülebilir bir düzeye getirebilmek için bir çalışma yapılmıştır. Mevcut DDA modelindeki STL harcamaları büyük bir artışa sebep olduğu için Access to Own adı verilen ATO modeli değerlendirilmiştir. Uygulamanın sonucunda kullanıcılara sunulan ekitapların çeşitliliği artmıştır. Ayrıca ilk analizler e-kitap koleksiyonlarının desteklenmesi için bunun sürdürülebilir ve düşük maliyetli bir yöntem olmaya devam edeceğini göstermiştir (Davies, 2017). Case Western Reserve Üniversitesinde mühendislik disiplinleri için çeşitli EBA modelleri ile bütçenin daha verimli kullanılması ve içerik erişiminin artırılması amaçlanmıştır. Uygulanan üç EBA modelinin karşılaştırılması yapılmış mühendislik alanında başarılı olan programların devam edebileceği başarısız olarak kabul edilen programların ise durdurulabileceği belirtilmiştir (Solomon ve Gray, 2018).

Yayıncı ve konu analizlerinin yapıldığı çalışmalara da literatürde yer verilmektedir. Hacettepe Üniversitesi Kütüphanelerinin abone olduğu bir veri tabanının kullanım ve konu analizinin yapıldı̆̆ 1 bir çalışmada, e-kitapların \%10'unun toplam talebin \%63'ünü ve en fazla talep edilen 20 kitabın ise toplam talebin \% 5 'ini karşıladığı görülmüştür ve genel olarak e-kitap kullanımının düşük olduğu ve kullanımın disiplinlere göre farklılık gösterdiği sonucuna ulaşılmıştır. Çalışmada seçim yapılırken kullanıcı özellikleri ile taleplerinin dikkate alınması ve kullanım analizi çalışmalarının düzenli olarak tekrarlanması gerektiği vurgulanmıştır (Al, Soydal ve Tonta, 2010). Nevada Üniversitesi Las Vegas Kütüphanelerinde ise satın alınan ekitap paketlerinin karşılaştırması yapılmış daha geniş ve güncel e-kitap paketlerinin kullanımının yüksek olduğu görülmüştür. Toplam kitap sayısı ile kullanılan kitaplar karşılaştırıldığında her iki pakette de aynı konu alanları en çok kullanılanlar arasında yer almıştır. Her iki paketin toplam kullanımına bakıldığında, kullanımı yüksek olan yayıncıların koleksiyonlarda daha büyük bir e-kitap yüzdesine sahip olduğu sonucuna ulaşılmıştır. Konu alanları ve yayıncılara yönelik eğilimlerin belirlenmesinde bu analizlerin kullanıcı davranışlarına 1şık tutacağı belirtilmiştir (Tucker, 2012).

Florida Üniversitesinde yapılan bir çalışmada maliyet ve kullanım verileri beşerî ve sosyal bilimler, fen-teknoloji-mühendislik-matematik ve tıp için karşılaştırarak farklı 
disiplinlerdeki satın alımların maliyet etkinliğini araştırılmıştır. En az satın alınan başlık ve en az kullanım oranına sahip tıp alanı, PDA modelinden en az yararlanan alan olmuştur. Diğer modellerde beşerî ve sosyal bilimler disiplinine ait e-kitapların büyük bir çoğunluğu kullanılmadığı için PDA modeli ile bu kitapların edinilmesinin daha verimli bir yöntem olduğu belirtilmiştir. Fen-teknoloji-mühendislik-matematik için paket alımlarda kullanılmayan e-kitap sayısı fazla olsa da ortalama ve birim kullanım maliyetleri bunun geçerli bir yöntem olduğunu göstermiştir (Carrico, Cataldo, Botero ve Shelton, 2015). Bir diğer çalışmada Iowa Üniversitesi Kütüphanelerinde PDA modelindeki STL seçeneği uygulanmış ve maliyetlerde önemli düşüşün olduğu görülmüştür. Yayıncı analizinde kullanıcıların üniversite yayınlarını ve güncel başlıkları daha fazla kullandığı ortaya çıkmıştır. Sadece bir defa kullanılmış başlıkları satın almak yerine STL ile sağlayarak maliyetin azaltılması istenmiş ancak ortalama maliyetlerin artış göstermesi üzerine STL seçeneklerinin devamı konusunda daha fazla verinin toplanması gerektiğine karar verilmiştir (Fischer, 2016).

\section{Amaç ve Yöntem}

Bu çalışmanın amacı Hacettepe Üniversitesi Kütüphanelerinin e-kitap kullanım istatistikleri ile maliyet verilerini değerlendirerek en uygun e-kitap sağlama modelinin belirlenmesidir. En uygun modelin belirlenebilmesi için senaryo analizi yapılmakta ve gerçek kullanım ve maliyet verilerine dayanarak e-kitap sağlama modellerinin farklı senaryolar altında nasıl çalıştığı ve nasıl bir maliyet performansı gösterdiği araştırılmaktadır. Çalışmada şu sorulara yanıt aranmıştır:

1. Hacettepe Üniversitesi Kütüphaneleri için paket olarak e-kitap sağlama modeli maliyet açısından uygun mudur?

2. Derleyici firma tarafından sunulan DDA modellerinin tercih edilmesi e-kitap alımları için yapılan toplam harcamaların maliyetini düşürmekte midir?

3. Yayıncı firma tarafından sunulan EBA modelinin tercih edilmesi e-kitap alımları için yapılan toplam harcamaların maliyetini düşürmekte midir?

4. Sağlama modellerinin seçimi disipline göre farklılık göstermekte midir?

Yayıncı firmadan satın alma modeli ile sağlanan e-kitapların kullanım verileri EBA ve abonelik modellerine, derleyici firmadan satın alma modeli ile sağlanan e-kitapların kullanım verileri otomatik satın almanın yapıldığ 1 ve STL'nin kullanıldığı DDA modellerine uyarlanarak maliyet ve konu analizleri yapılmıştır. ${ }^{1}$ Çalışma için gerekli veriler yönetici hesapları ile yayıncı ve derleyici firmadan sağlanmıştır.

Hacettepe Üniversitesi (HÜ) Kütüphaneleri tarafından 2013 yılında yayıncı firmadan farklı konu alanlarında ve yayın yılı 2005-2013 aralığında olan 36.657 e-kitap satın alınmıştır. Analizlerin yapılmasında tüm yayın yıllarına ait e-kitaplar değerlendirmeye alınamamıştır. Çünkü yayıncıdaki EBA modelinde, yayın yılı geriye dönük olarak sadece son üç yılı kapsayan güncel koleksiyonlar erişime açılmaktadır. Örneğin 2019 yılında erişime açılan bir EBA modelinde 2016-2017-2018 yayın yılına ait e-kitaplar bulunmaktadır. Bu çalışmada ise tüm satın alınan e-kitaplardan sadece yayın yılı 2011, 2012 ve 2013 (15.564 adet) olanların 2014 yılında satın alındığı kabul edilmekte ve e-kitapların 2014-2017 yılları arasındaki kullanım

\footnotetext{
${ }^{1}$ E-kitapların kullanım ve maliyet verileri gerçek veriler ışı̆̆ında değerlendirilmiş sadece gerçekte 2013 olan satın alma yılı, derleyici firmada 2016, yayıncı firmada 2014 olarak kabul edilmiştir.
} 
verileri EBA ve abonelik modeline uyarlanarak maliyet ve konu analizi yapılmaktadır. Çalışmamız kapsamında değerlendirilen 2011-2012-2013 yayın yıllarına ait kitapların paket fiyatından ilk alımda yapılan indirim oranı düşülmüş ve 15.564 e-kitabın 2014 yılı paket olarak satın alma bedeli 484.880,88 € olarak hesaplanmıştır. Kullanılan kitapların bireysel başlık halinde tek tek satın alınması durumundaki maliyet karşılaştırmasını yapabilmek için ihtiyaç duyulan liste fiyatları ise yayıncı firmadan sağlanmıştır.

HÜ Kütüphaneleri tarafından 2013 yılında derleyici firmadan farklı yayınevleri ve yıllara ait 3.666 e-kitap satın almıştır. Derleyici firmadaki platform değişikliği sebebiyle sadece 20162018 yıllarına ait kullanım istatistikleri temin edilebilmiş ve bu aralıktaki kullanım verileri değerlendirilmiştir. İhtiyaç duyulan paket ve liste fiyatları için derleyici firmadan sadece 2018 yılı paket fiyatı sağlanabilmiş, 2018 yılı liste fiyatları ise tek tek e-kitaplar için ilgili derleyicinin satın alma platformundan alınmıştır. Bu veriler doğrultusunda 2018 yılı paket fiyatından 2013 yılı paket fiyatı çıkarılarak beş yıl için toplam fark bulunmuş ve bu fark tek bir yıla oranlanarak bir yılda paket fiyatının üzerine derleyici firma tarafından ne kadar ücret farkı eklendiği hesaplanmıştır. Yıllara göre liste fiyatını belirleyebilmek için ise 2018 yılı paket fiyatından 2018 y1lı liste fiyatına yüzde kaç artış olduğu hesaplanmış ve bu artış miktarı her bir yıl için bulunan paket fiyatları üzerine eklenerek liste fiyatları bulunmuştur. DDA modeli belirli sayıda kullanım ile otomatik satın almanın gerçekleşmesi ve belirli sayıda STL kullanımı sonrası otomatik satın almanın gerçekleşmesi şeklinde iki farklı senaryo olarak uygulanmıştır. Derleyici firmada STL maliyeti, kitabın kullanıcıya bir günlüğüne ödünç verilmesi şeklinde anlaşma yapılmışsa kitabın liste fiyatının \%15'i, 7 gün için \%20'si, 14 gün için \%25'i, 28 gün için \%30'u olarak alınmaktadır. STL maliyetleri bu alternatiflerin tamamı için ayrı ayrı hesaplanmıştır.

Satın alınan e-kitap listesinde konu alanlarını belirleyebilmek için Web of Science'ın konu sınıflamasından yararlanılmıştır. Sadece LC numaraları bulunan kitapların konu alanları ise LC sınıflama sistemine göre A-P ve TR-Z sınıfları için sosyal ve beşerî bilimler; Q ve S-TP sınıfları için fen, mühendislik, teknoloji, matematik ve R sınıfı için tıp ve sağlık bilimleri şeklinde alınmıştır.

Derleyici ve yayıncı firmanın birim kullanım ve ortalama kitap maliyetini hesaplayabilmek için aşağıdaki formüllere dayanarak hesaplamalar yapılmıştır. Formülde $B K M$; birim kullanım maliyetini, $O K M$; ortalama kitap maliyetini, $M$ e-kitapların toplam satın alma maliyetini, $K$ e-kitapların belirlenen yıl aralığındaki toplam kullanım sayısını, $S$ ise satın alınan kitap sayısını ifade etmektedir.

$$
\begin{aligned}
& B K M=M / K \\
& O K M=M / S
\end{aligned}
$$




\section{Bulgular ve Yorum}

Konu ve maliyet analizi yayıncı ve derleyici firma tarafından sunulan e-kitap sağlama modellerine göre değerlendirilmektedir.

\section{Yayıncı Firma}

HÜ Kütüphaneleri tarafından 2014 yılında yayın yılı 2011, 2012 ve 2013 olan 15.564 e-kitap 484.880,88 € ödeme yapılarak satın alınmıştır. Bu e-kitaplar yayıncı firmanın sunduğu satın alma, EBA ve abonelik modellerine göre değerlendirilmiştir.

\section{Satın Alma Modeli}

Satın alma modeli ile sağlanan 15.564 e-kitabın 8.751'i (\%56) kullanılmış ve 2014-2017 yılları arasında bu e-kitaplardan 298.968 bölüm indirilmiştir (Tablo 1). Paketteki kitapların \%44'ü $(N=6.813)$ hiç kullanılmamıştır.

Tablo 1

E-kitaplardan indirilen bölüm ve kullanılan tekil e-kitap sayısı

\begin{tabular}{crrr}
\hline \multirow{2}{*}{ Yıl } & \multicolumn{2}{c}{ Índirilen bölüm sayısı } & \multicolumn{2}{c}{ Tekil e-kitap sayısı } \\
\cline { 2 - 4 } & \multicolumn{1}{c}{$\mathbf{N}$} & $\boldsymbol{\%}$ & $\mathbf{N}$ \\
\hline 2014 & 61.293 & 20,5 & 3.448 \\
2015 & 104.151 & 34,8 & 5.482 \\
2016 & 70.803 & 23,7 & 3.295 \\
2017 & 62.721 & 21,0 & 2.562 \\
\hline Toplam & 298.968 & 100,0 & $* 8.751$ \\
\hline
\end{tabular}

Not: *2014-2017 yılları arasında kullanılan toplam tekil e-kitap sayısını göstermektedir. Sütun toplamı değildir.

2014-2017 yılları arasında en az bir defa kullanılan 8.751 kitap ile ilgili dağılım Şekil 1'de gösterilmektedir. Paketteki kitapların sadece \%8'i $(N=731)$ toplam kullanımın \%50'sini, \%27'si ise $(N=2.382)$ \%81'ini karşılamaktadır. Satın alınan kitapların yaklaşık üçte birinden ihtiyacın \%80'i sağlanmıştır. Ashcroft (2011), Grigson (2011) ve Soules'un (2009) da belirttiği gibi paket halinde alımlar az kullanılacak ya da hiç kullanılmayacak materyallerin kütüphane koleksiyonuna eklenmesine sebep olabilmektedir.

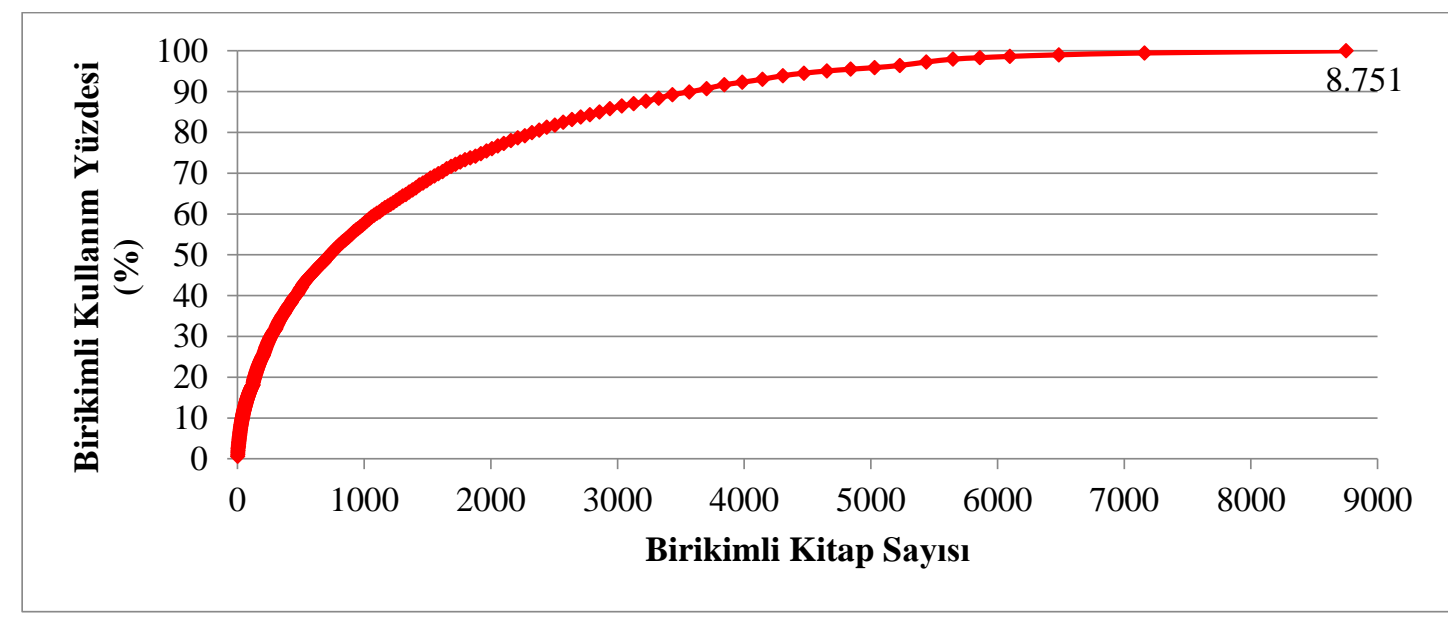

Şekil 1. 2014-2017 yılları arasında kullanılan e-kitapların dağılımı

Tablo 1'de kullanımları verilen e-kitapların birim kullanım (BKM) ile ortalama kitap maliyeti (OKM) aşağıdaki gibi bulunmuştur (2014 yılı paket olarak satın alma bedeli 
484.880,88 $€$ 'dur). Satın alma maliyeti yüksek olsa da toplam kullanımlar birim kullanım maliyetini etkilemiştir.

$$
\begin{aligned}
& B K M=M / K \rightarrow B K M=484.880,88 / 298.968 \rightarrow \quad B K M=1,62 € \\
& O K M=M / S \rightarrow O K M=484.880,88 / 15.564 \rightarrow O K M=31,15 €
\end{aligned}
$$

\section{Konu Analizi}

E-kitapların konu alanlarına göre dağılımı incelenmiş ve birim kullanım maliyetleri hesaplanmıştır. En yüksek kullanım değerine $(\% 21,4)$ sahip tıp alanı için satın alınan kitap sayısının kullanımın yoğunluğunu etkilemediğini söyleyebiliriz (Tablo 2). Bununla birlikte en az kitap sayısı $(\% 0,8)$ ve en az kullanımın $(\% 0,5)$ görüldüğü konu alanı enerji olmuştur. Ancak enerji konu alanının sadece yayın yılı 2013 olan kitapların içinde yer aldığı ve kitap sayısı ile kullanımının bu sebeple düşük olduğu söylenebilir. Birim kullanım maliyetinde ise en düşük maliyetin $(0,64 €)$ davranış bilimlerinde olması en az ödemenin $(\% 0,9)$ bu konu alanına yapılması ile açıklanabilir. Disipline göre kitapların fiyatı maliyetleri etkilemektedir. Birikmiş kullanımlar devam ettikçe mevcut olan birim kullanım maliyetlerinin daha da düşük bir değer göstereceği gözden kaçırılmamalıdır.

Tablo 2

\begin{tabular}{|c|c|c|c|c|c|c|c|c|c|}
\hline \multirow{2}{*}{ Konu alanları } & \multicolumn{2}{|c|}{$\begin{array}{l}\text { Satın alınan } \\
\text { kitap sayısı }\end{array}$} & \multicolumn{2}{|c|}{$\begin{array}{c}\text { Kullanılan kitap } \\
\text { sayısı }\end{array}$} & \multicolumn{2}{|c|}{$\begin{array}{c}\text { İndirilen bölüm } \\
\text { sayısı }\end{array}$} & \multicolumn{2}{|c|}{$\begin{array}{c}\text { Fiyat } \\
(€)\end{array}$} & \multirow[t]{2}{*}{$\begin{array}{c}\text { BKM } \\
(€)\end{array}$} \\
\hline & $\mathbf{N}$ & $\%$ & $\mathbf{N}$ & $\%$ & $\mathbf{N}$ & $\%$ & $\mathbf{N}$ & $\%$ & \\
\hline Davranış Bilimleri & 235 & 1,5 & 153 & 1,7 & 7.105 & 2,4 & $4.525,00$ & 0,9 & 0,64 \\
\hline Tip & 1.450 & 9,3 & 1.061 & 12,1 & 64.044 & 21,4 & $51.703,00$ & 10,7 & 0,81 \\
\hline Bilgisayar Bilimleri & 3.113 & 20,0 & 1.942 & 22,2 & 62.256 & 20,8 & $69.466,00$ & 14,3 & 1,12 \\
\hline $\begin{array}{l}\text { Biyomedikal ve Yaşam } \\
\text { Bilimleri }\end{array}$ & 1.466 & 9,4 & 867 & 9,9 & 35.329 & 11,8 & $56.152,00$ & 11,6 & 1,59 \\
\hline Çevre ve Yer Bilimleri & 819 & 5,3 & 446 & 5,1 & 16.592 & 5,5 & $28.861,00$ & 5,9 & 1,74 \\
\hline İşletme ve Ekonomi & 978 & 6,3 & 474 & 5,4 & 11.941 & 4,0 & $22.381,00$ & 4,6 & 1,87 \\
\hline Mühendislik & 2.227 & 14,3 & 1.322 & 15,1 & 32.504 & 10,9 & $63.162,00$ & 13,0 & 1,94 \\
\hline $\begin{array}{l}\text { Beşerî ve Sosyal Bilimler ve } \\
\text { Hukuk }\end{array}$ & 1.678 & 10,8 & 867 & 9,9 & 25.645 & 8,6 & $50.911,00$ & 10,5 & 1,99 \\
\hline Kimya ve Malzeme Bilimi & 683 & 4,4 & 406 & 4,6 & 15.851 & 5,3 & $38.200,00$ & 7,9 & 2,41 \\
\hline Matematik ve İstatistik & 1.432 & 9,2 & 545 & 6,2 & 13.418 & 4,5 & $36.493,00$ & 7,5 & 2,72 \\
\hline Enerji & 128 & 0,8 & 81 & 0,9 & 1.517 & 0,5 & $5.470,88$ & 1,1 & 3,61 \\
\hline $\begin{array}{l}\text { Mesleki ve Uygulamalı } \\
\text { Bilişim }\end{array}$ & 456 & 2,9 & 179 & 2,0 & 5.049 & 1,7 & $20.169,00$ & 4,2 & 3,99 \\
\hline Fizik ve Astronomi & 899 & 5,8 & 408 & 4,7 & 7.717 & 2,6 & $37.387,00$ & 7,7 & 4,84 \\
\hline Toplam & 15.564 & 100,0 & 8.751 & 100,0 & 298.968 & 100,0 & $484.880,88$ & 99,9 & - \\
\hline
\end{tabular}

2014 yılında satın alındı̆̆ kabul edilen e-kitapların konu alanlarına göre dă̆ılımı ve maliyeti

Not 1: Yuvarlama hatasından dolayı bazı toplamlar \%100'den farklıdır.

Not 2: BKM: Birim Kullanım Maliyeti

\section{EBA Modeli (Kanıta Dayalı Săglama)}

Yayıncı firmadaki EBA Modelinde bir yılın sonunda ödenen miktar kadar e-kitap seçimi, kitapların tek tek liste fiyatlarına göre değil kitap türüne göre belirlenmiş EBA fiyatları üzerinden yapılmaktadır (Tablo 3). 
Tablo 3

Yayln türüne göre EBA fiyat listesi

\begin{tabular}{lrl}
\hline Tür & EBA fiyatı (€) & Açılama \\
\hline Ders kitabı & 389 & Lisans ve lisansüstü ders kitabı, Almanca ders kitabı \\
Referans Kaynakları & Liste fiyatı & Sözlük, el kitabı, ansiklopedi, referans, atlas \\
Özet & 49 & Özet \\
Araştırma & 169 & Monograf, çok yazarlı kitaplar, bildiriler, doktora tezi, inceleme vb. \\
\hline
\end{tabular}

E-kitapların 2014 yılı gerçek kullanımları en yüksek kullanımdan en düşük kullanıma doğru sıralanmış ve 115.500,00 € (yayıncı tarafından gönderilen 2014 yılı EBA ücreti) tutarında e-kitap seçiminin yapılması sağlanmıştır. Eğer bu model 2014 yılında uygulanmış olsaydı yayın y1l 2011-2012-2013 olan toplam 557 e-kitap satın alınabilecek ve 115.499,19 $€$ ödeme yapılması gerekecekti (Tablo 4). 557 e-kitabın bu model dışındaki toplam liste fiyatı ise 104.403,78 $€$ olarak hesaplanmıştır. EBA fiyatı ile liste fiyatı arasındaki fark 11.095,41 $€$ 'dur. Liste fiyatı daha uygun olmasına rağmen seçilen kitapların kullanımının tahmin edilememesi, EBA modeli ile daha isabetli seçimlerin yapılmasını mümkün kılmıştır.

Tablo 4

2014 yılında EBA modeli ile satın alındi ̆̆ kabul edilen e-kitapların maliyeti

\begin{tabular}{lrrrr}
\hline Tür & EBA fiyatı (€) & Adet & EBA maliyeti (€) & Toplam liste fiyatı (€) \\
\hline Atlas & Liste Fiyatı & 8 & $1.842,86$ & $1.842,86$ \\
Özet & 49,00 & 2 & 98,00 & 104,94 \\
Derleme & 169,00 & 1 & 169,00 & 249,99 \\
Çok yazarlı kitap & 169,00 & 164 & $27.716,00$ & $31.416,06$ \\
Sözlük & Liste Fiyatı & 2 & 559,98 & 559,98 \\
Ansiklopedi & Liste Fiyatı & 5 & $11.399,96$ & $11.399,96$ \\
Lisans ve lisansüstü ders kitabı & 389,00 & 30 & $11.670,00$ & $2.128,51$ \\
El kitabı & Liste Fiyatı & 34 & $9.848,45$ & $9.848,45$ \\
Kılavuz & Liste Fiyatı & 3 & 209,97 & 209,97 \\
Monograf & 169,00 & 91 & $15.379,00$ & $15.366,05$ \\
Bildiri & 169,00 & 146 & $24.674,00$ & $21.683,03$ \\
Uzmanlık kitabı & 169,00 & 64 & $10.816,00$ & $8.219,05$ \\
Referans kaynağ1 & 289,98 & 289,98 \\
İnceleme & 169,00 & 3 & 289,98 \\
Popüler bilim & 169,00 & 1 & 507,00 & 909,97 \\
Yıllık & Liste Fiyatı & 1 & 169,00 & 24,99 \\
\hline Toplam & & $\mathbf{5 5 7}$ & $\mathbf{1 1 5 . 4 9 9 , 1 9}$ & 149,99 \\
\hline
\end{tabular}

Not: EBA modelinde kitap türüne göre fiyatlar sabittir ancak liste fiyatında her bir kitabın fiyatı birbirinden farklıdır.

2014-2017 yılları arasında EBA modeli ile sağlandığı kabul edilen 557 farklı e-kitaptan 79.032 bölüm indirilmiştir. EBA modeli garantili harcamaların yapılması için uygulanmasına rağmen sadece bir yılın kullanımı sonraki yılların kullanımına garanti vermeyebilir. Örneğin, kullanımın yarısından fazlası $(\% 54,1)$ ilk yıl gerçekleşirken, geriye kalan kullanım ise $(\% 45,9)$ sonraki üç yılda gerçekleşmiştir. Satın alınan kitaplardan indirilen bölüm sayısı ve kullanılan tekil e-kitap sayısının yıldan yıla azaldığı görülmüsstür (Tablo 5). Uzun süreli kullanımı olabilecek kitaplar için bu modelin tercih edilmesinde fayda vardır. 
Tablo 5

E-kitaplardan indirilen bölüm ve kullanılan tekil e-kitap saylsı

\begin{tabular}{crrr}
\hline \multirow{2}{*}{ Yıl } & \multicolumn{2}{c}{ İndirilen bölüm sayısı } & \multicolumn{2}{c}{ Tekil e-kitap sayıSı } \\
\cline { 2 - 4 } & \multicolumn{1}{c}{$\mathbf{N}$} & \multicolumn{1}{c}{$\mathbf{\%}$} & $\mathbf{N}$ \\
\hline 2014 & 42.761 & 54,1 & 557 \\
2015 & 16.385 & 20,7 & 370 \\
2016 & 9.641 & 12,2 & 258 \\
2017 & 10.245 & 13,0 & 220 \\
\hline Toplam & $\mathbf{7 9 . 0 3 2}$ & $\mathbf{1 0 0 , 0}$ & $* \mathbf{5 5 7}$ \\
\hline
\end{tabular}

Not: *2014-2017 yılları arasında kullanılan toplam tekil e-kitap sayısını göstermektedir. Sütun toplamı değildir.

Şekil 2. EBA modeli ile kullanılan e-kitapların dağılımı'de EBA modeline göre en az bir defa kullanılmış e-kitapların birikimli kullanım yüzdesi gösterilmektedir. Toplam kullanımın yarısı 3.448 kitabın sadece \%8'inden ( $N=267)$, \%69'u ise \%16'sından $(N=559)$ karşılanmıştır. EBA modeli ile satın alınan 557 kitabın toplam kullanımın üçte ikisinden fazlasını karşıladığı, bir başka deyişle en çok kullanılan kitapların satın alındığı görülmektedir.

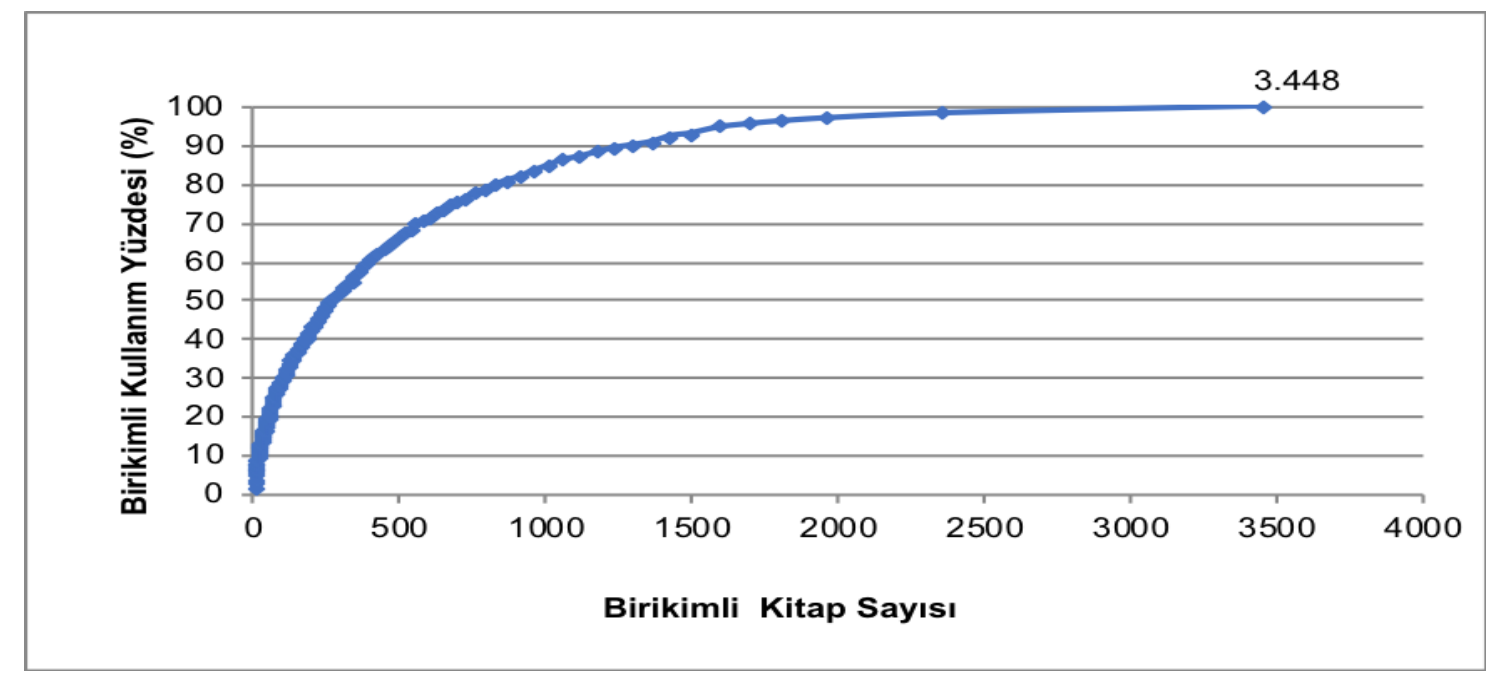

Şekil 2. EBA modeli ile kullanılan e-kitapların dă̆ılımı

EBA modelinde birim kullanım maliyeti hesaplanırken modelin uygulandığı yılda erişilen tüm e-kitapların toplam kullanımı ile o yılın sonunda satın alınan kitapların sonraki yıllarda kullanımları dikkate alınmıştır. Buna göre 2014 yılında uygulandığı kabul edilen EBA modelinde erişilen tüm kitapların kullanımı $(N=18.532)$ ile o yılın sonunda satın alınan 557 ekitabın 2014-2017 yılları arasındaki kullanımı $(N=79.032) 97.564$ olmuştur. EBA modeli ile sağlanan e-kitapların birim kullanım maliyeti ise aşağıdaki gibi hesaplanmıştır:

$$
B K M=M / K \rightarrow B K M=115.499,19 / 97.564 \rightarrow B K M=1,18 €
$$

E-kitapların paket olarak satın alma modelinde birim kullanım maliyeti 1,62 $€$, EBA modelinde ise 1,18€ olarak hesaplanmıştır. Satın alma modelinde ödenen miktar fazla olmasına rağmen birim kullanım maliyetinin çok yüksek çıkmaması 2014-2017 yılları arasındaki toplam kullanımların fazla olmasından kaynaklanmaktadır. EBA modelinde ise paket fiyatına göre daha az bir ödeme yapıldığ 1 ve sadece kullanımı olan kitaplar alındığı için birim kullanım maliyeti düşük çıkmıştır. 


\section{Konu Analizi}

EBA modeli kapsamında en fazla kitabın satın alındığ konu alanı tıp $(\% 27,5)$ olurken 2014 yılı boyunca kullanılan 3.448 kitabın içinde en fazla kitabın erişildiği konu alanı ise bilgisayar bilimleridir $(\% 25,8)$. Satın alınan ve satın alma yapılmadan sadece erişilen e-kitap sayısı ile indirilen bölüm sayısı en fazla tıp ve bilgisayar bilimlerinde görülmüştür (Tablo 6). Ancak bu alanların en düşük birim kullanım maliyetine sahip olmaması maliyetlerinin yüksek olması ile açıklanabilir. Kullanıma dayalı seçimlerin yapılması bütün konu alanlarında genel olarak çok yüksek birim kullanım maliyetleri ile karşılaşılmasını engellemiştir.

Tablo 6

EBA modeli ile satın alındı̆̆ kabul edilen e-kitapların konu alanlarına göre dă̆ılımı, kullanımı ve birim kullanım maliyeti (BKM)

\begin{tabular}{|c|c|c|c|c|c|c|c|c|c|}
\hline \multirow[t]{2}{*}{ Konu alanları } & \multicolumn{2}{|c|}{$\begin{array}{l}\text { Satın alınan } \\
\text { kitap sayısı }\end{array}$} & \multicolumn{2}{|c|}{$\begin{array}{l}\text { Kullanılan } \\
\text { kitap sayısı }\end{array}$} & \multicolumn{2}{|c|}{$\begin{array}{c}\text { EBA maliyeti } \\
(€)\end{array}$} & \multicolumn{2}{|c|}{$\begin{array}{c}\text { Toplam } \\
\text { indirilen bölüm } \\
\text { sayısı }\end{array}$} & \multirow{2}{*}{$\begin{array}{c}\text { BKM } \\
(\boldsymbol{\epsilon})\end{array}$} \\
\hline & $\mathbf{N}$ & $\%$ & $\mathbf{N}$ & $\%$ & $\mathbf{N}$ & $\%$ & $\mathbf{N}$ & $\%$ & \\
\hline Davranış Bilimleri & 15 & 2,7 & 71 & 2,1 & $4.639,95$ & 4,0 & 2.731 & 2,8 & 1,70 \\
\hline Biyomedikal ve Yaşam Bilimleri & 83 & 14,9 & 342 & 9,9 & $16.595,31$ & 14,4 & 13.377 & 13,7 & 1,24 \\
\hline İşletme ve Ekonomi & 15 & 2,7 & 175 & 5,1 & $2.945,99$ & 2,5 & 3.682 & 3,8 & 0,80 \\
\hline Kimya ve Malzeme Bilimi & 13 & 2,3 & 155 & 4,5 & $3.778,99$ & 3,3 & 2.503 & 2,6 & 1,51 \\
\hline Bilgisayar Bilimleri & 117 & 21,0 & 891 & 25,8 & $20.766,96$ & 18,0 & 19.315 & 19,8 & 1,07 \\
\hline Çevre ve Yer Bilimleri & 30 & 5,4 & 158 & 4,6 & $11.359,15$ & 9,8 & 6.317 & 6,5 & 1,80 \\
\hline Mühendislik & 43 & 7,7 & 584 & 16,9 & $8.184,17$ & 7,1 & 10.199 & 10,4 & 0,80 \\
\hline $\begin{array}{l}\text { Beşerî ve Sosyal Bilimler ve } \\
\text { Hukuk }\end{array}$ & 44 & 7,9 & 274 & 7,9 & $11.722,93$ & 10,1 & 6.833 & 7,0 & 1,71 \\
\hline Matematik ve İstatistik & 19 & 3,4 & 156 & 4,5 & $4.962,98$ & 4,3 & 2.772 & 2,8 & 1,79 \\
\hline Tip & 153 & 27,5 & 458 & 13,3 & $25.657,76$ & 22,2 & 26.458 & 27,1 & 0,97 \\
\hline Fizik ve Astronomi & 14 & 2,5 & 90 & 2,6 & $3.026,00$ & 2,6 & 1.688 & 1,7 & 1,79 \\
\hline Mesleki ve Uygulamalı Bilişim & 11 & 2,0 & 76 & 2,2 & $1.859,00$ & 1,6 & 1.588 & 1,6 & 1,17 \\
\hline Enerji & - & - & 18 & 0,5 & - & & 101 & 0,1 & -- \\
\hline Toplam & 557 & 100,0 & 3.448 & 999 & $115.499,19$ & 99,9 & 97.564 & 999 & \\
\hline
\end{tabular}

Not 1: Yuvarlama hatasından dolayı bazı toplamlar \%100'den farklıdır. Not 2: BKM: Birim Kullanım Maliyeti

\section{Abonelik Modeli (Sadece Erişim-Access Only)}

Yayıncı firmada satın alma fiyatının \%30'u ödenerek kurumlar abonelik modeli ile koleksiyonlara erişim sağlayabilmektedir. Ancak abonelikte sadece anlaşmanın yapıldığı tarih aralığında koleksiyona erişim hakkı bulunduğu için karşılaştırmayı doğru yapabilmek adına 2015-2016-2017 yıllarında da erişimin devam ettiği varsayılmıştır. Aboneliğin devamı durumunda yıllık artış bilgisi yayıncı tarafından \%3 olarak onaylanmış ve abonelik bedelleri bu artışa göre hesaplanmıştır (Tablo 7).

Tablo 7

E-kitaplardan indirilen bölüm sayısı ve yıllık abonelik ücretleri

\begin{tabular}{crrr}
\hline \multirow{2}{*}{ Yıl } & \multicolumn{2}{c}{$\begin{array}{c}\text { Indirilen bölüm } \\
\text { sayısı }\end{array}$} & \multirow{2}{*}{ Abonelik ücreti (€) } \\
\cline { 2 - 3 } & \multicolumn{1}{c}{$\mathbf{N}$} & \multicolumn{1}{c}{$\%$} & \\
\hline 2014 & 61.293 & 20,5 & $145.464,26$ \\
2015 & 104.151 & 34,8 & $149.828,19$ \\
2016 & 70.803 & 23,7 & $154.323,04$ \\
2017 & 62.721 & 21,0 & $158.952,73$ \\
\hline Toplam & $\mathbf{2 9 8 . 9 6 8}$ & $\mathbf{1 0 0 , 0}$ & $\mathbf{6 0 8 . 5 6 8 , 2 2}$ \\
\hline
\end{tabular}


Kitapların birim kullanım maliyeti ise aşağıdaki gibi hesaplanmıştır:

$B K M=M / K \rightarrow B K M=608.568,22 / 298.968 \rightarrow B K M=2,04 €$

Grigson'un da (2011) belirttiği gibi satın alma modeli ile sağlanan e-kitaplar bir abonelik dönemi için ödemesi yapılan e-kitaplardan daha pahalıdır ancak modeller arasındaki karşılaştırmanın yapılabilmesi için abonelik modelinde dört yıl boyunca erişimin sağlanması toplam maliyet ile birim kullanım maliyetlerinin yükselmesine neden olmuştur.

Yayıncı firmanın sunduğu EBA modeli için (sürekli ve sadece erişim) birim kullanım maliyeti $1,18 €$, satın alma/paket (sürekli erişim) modeli için 1,62 $€$ ve abonelik modeli (sadece erişim) için 2,04 $€$ olarak hesaplanmıştır. Modeller arasında en düşük birim kullanım maliyeti EBA'da en yüksek birim kullanım maliyeti ise abonelik süresi sona erdiğinde erişim hakkı bulunmayan abonelik modelinde görülmüştür. Buna göre yayıncı firmanın sunduğu EBA modelinin hem birim kullanım maliyeti hem de toplam harcama maliyeti açısından karşılaştırılan modeller arasında en ekonomik ve kullanıcı ihtiyacına yönelik isabetli kararların verilmesine yardımcı olduğu için de en uygun model olduğunu söylemek mümkündür.

\section{Derleyici Firma}

HÜ Kütüphaneleri tarafından 2013 yılında farklı yayınevleri ve yıllara ait 3.666 e-kitap derleyici firmadan satın alınmış ve 300.174,00 \$ ödeme yapılmıştır. Araştırmanın amaç ve yöntem kısmında da belirtildiği üzere derleyici firmaya ait paket ve liste fiyatları artış oranları dikkate alınarak hesaplanmıştır (Tablo 8).

Tablo 8

Derleyici firma e-kitaplarının paket ve liste fiyatları

\begin{tabular}{rrr}
\hline Yıl & Paket fiyatı (\$) & Liste fiyatı (\$) \\
\hline 2013 & $300.174,00$ & $372.344,83$ \\
2014 & $304.765,36$ & $378.040,10$ \\
2015 & $309.356,72$ & $383.735,36$ \\
2016 & $313.948,08$ & $389.430,62$ \\
2017 & $318.539,44$ & $395.125,88$ \\
2018 & $323.130,80$ & $400.820,70$ \\
\hline
\end{tabular}

\section{Satın Alma Modeli (Sürekli Erişim)}

Satın alınan kitapların 2016-2018 yılları arasındaki kullanımları istatistik türü dikkate alınarak değerlendirilmiştir. En çok e-kitap kullanımı çevrimiçi görüntüleme $(\% 45,2)$ ile ayrıntılı kayıt görüntülemede $(\% 39,3)$, en düşük kullanım ise kaydetme isteğinde $(\% 0,1)$, e-posta isteğinde $(\% 0,5)$ ve bölüm indirmede $(\% 0,8)$ görülmektedir (Tablo 9). Bu istatistikler kullanıcıların daha kısa zamanda sonuca götürecek olan çevrimiçi veya ayrıntılı kayıt görüntüleme seçeneklerini tercih ettiğini göstermektedir. 
Tablo 9

Satın alınan e-kitapların kullanım istatistiği türü (2016-2018)

\begin{tabular}{|c|c|c|c|c|c|c|c|c|}
\hline \multirow{3}{*}{ İstatistik türü } & \multicolumn{6}{|c|}{ Yıllara göre kullanım } & \multirow{2}{*}{\multicolumn{2}{|c|}{ Toplam kullanım }} \\
\hline & \multicolumn{2}{|c|}{2016} & \multicolumn{2}{|c|}{2017} & \multicolumn{2}{|c|}{2018} & & \\
\hline & $\mathbf{N}$ & $\%$ & $\mathbf{N}$ & $\%$ & $\mathbf{N}$ & $\%$ & $\mathbf{N}$ & $\%$ \\
\hline Bölüm indirme & 0 & 0 & 0 & 0 & 78 & 4,2 & 78 & 0,8 \\
\hline Tam indirme & 361 & 7,8 & 317 & 8,5 & 140 & 7,5 & 818 & 8,0 \\
\hline Çevrimiçi görüntüleme & 1.963 & 42,4 & 1.731 & 46,4 & 933 & 50,0 & 4.627 & 45,2 \\
\hline Yazdırma isteği & 280 & 6,0 & 281 & 7,5 & 65 & 3,5 & 626 & 6,1 \\
\hline E-posta isteği & 18 & 0,4 & 24 & 0,6 & 10 & 0,5 & 52 & 0,5 \\
\hline Kaydetme isteği & 2 & 0 & 5 & 0,1 & 0 & 0 & 7 & 0,1 \\
\hline Ayrıntılı kayıt görüntüleme & 2.005 & 43,3 & 1.375 & 36,8 & 640 & 34,3 & 4.020 & 39,3 \\
\hline Toplam & 4.629 & 99,9 & 3.733 & 99,9 & 1.866 & $\overline{100,0}$ & 10.228 & $\overline{100,0}$ \\
\hline
\end{tabular}

Not: Yuvarlama hatasından dolayı bazı toplamlar \%100'den farklıdır.

Satın alınan 3.666 kitaptan 783 kitabın 2016 yılında 4.629 kullanımı, 722 kitabın 2017 yılında 3.733 kullanımı, 590 kitabın 2018 yılında 1.866 kullanımı olmuştur. 2016-2018 yılları arasında kullanılan toplam tekil e-kitap sayısı 1.489 iken 10.228 toplam kullanımı olmuştur. Derleyici firmadaki platform değişikliği sebebiyle tüm istatistikler temin edilememiş ve ekitapların 2016 yılında alındığı kabul edilmiştir. Ancak 2013 yılında satın alınan bu kitapların ilk yıllardaki kullanımlarının yüksek olabileceği ve bu durumunda maliyetleri daha aşağ 1 çekebileceği ihtimali gözden kaçırılmamalıdır.

Kullanılan kitaplara ilişkin birikimli kullanım yüzdesi Şekil 3'te gösterilmektedir. Satın alınan kitapların $(N=3.666)$ sadece \%41'i $(N=1.489)$ kullanılmıştır. Toplam kullanımın (10.228) \%51'ini 1.489 kitabin sadece \%10,5'i $(N=157)$, \%79'unu ise \%32'si $(N=480)$ karşılamıştır. Kullanımın az sayıda kitapta yoğunlaştığı görülmektedir.

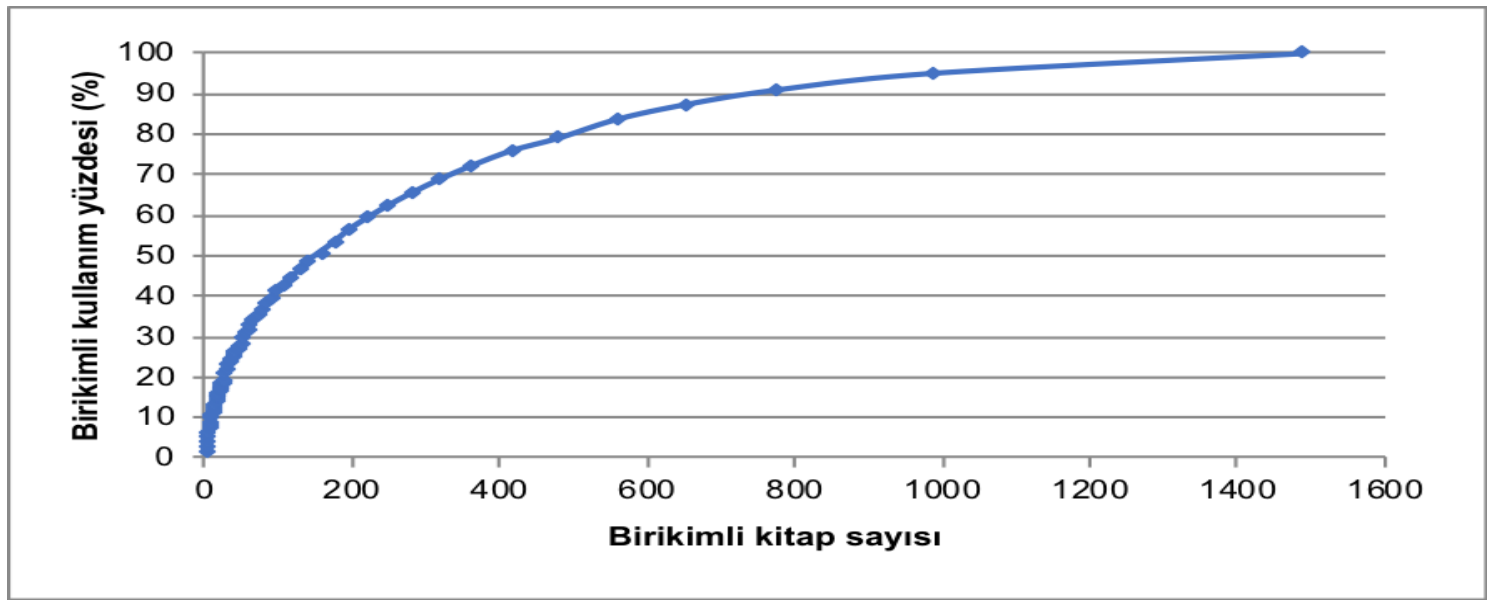

Şekil 3. 2016-2018 yılları arasında kullanılan e-kitapların dağılımı

2016 yılında satın alınan e-kitapların birim kullanım ve ortalama kitap maliyeti aşağıdaki gibi hesaplanmıştır:

$$
\begin{aligned}
& B K M=M / K \rightarrow B K M=313.948,08 / 10.228 \rightarrow \quad B K M=30,69 \$ \\
& O K M=M / S \rightarrow O K M=313.948,08 / 3.666 \rightarrow O K M=85,64 \$
\end{aligned}
$$

2016 yılında e-kitapların bireysel başlık halinde tek tek satın alındığının kabul edilmesi durumunda birim kullanım ve ortalama kitap maliyeti ise aşağıdaki gibi hesaplanmıştır: 


$$
\begin{aligned}
& B K M=M / K \rightarrow B K M=389.430,62 / 10.228 \rightarrow \quad B K M=38,07 \$ \\
& O K M=M / S \rightarrow O K M=389.430,62 / 3.666 \rightarrow O K M=106,23 \$
\end{aligned}
$$

Paket halinde satın alınan e-kitapların ortalama kitap ve birim kullanım maliyeti bireysel başlık halinde satın alınan e-kitaplara göre daha düşük çıkmıştır. Ancak paket halinde satın alınan e-kitapların yarısından daha azı kullanılmış ve az sayıda başlığın ihtiyacın büyük bir çoğunluğunu karşıladığı görülmüştür.

\section{Konu Analizi}

Satın alınan e-kitapların konu alanlarına göre dağılımı Tablo 10' da gösterilmektedir. Sosyal ve beşerî bilimlerin, toplam kullanımın yaklaşık dörtte üçünü oluşturması satın alınan kitap sayısının fazla olmasıyla açıklanabilir. Satın alınan kitapların \%8'i ile toplam kullanımın \%15'inin tıp ve sağlık bilimlerinde olması bu disiplinde kitap sayısına göre kullanımın yüksek olduğunu göstermektedir.

Tablo 10

\begin{tabular}{|c|c|c|c|c|c|c|c|c|c|c|c|c|}
\hline \multirow{3}{*}{ Konu } & \multirow{2}{*}{\multicolumn{2}{|c|}{$\begin{array}{l}\text { Kitap } \\
\text { sayısı }\end{array}$}} & \multicolumn{8}{|c|}{ Yıllara göre kullanım } & \multirow{2}{*}{\multicolumn{2}{|c|}{ Fiyat (\$) }} \\
\hline & & & \multicolumn{2}{|c|}{2016} & \multicolumn{2}{|c|}{2017} & \multicolumn{2}{|c|}{2018} & \multicolumn{2}{|c|}{ Toplam } & & \\
\hline & $\mathbf{N}$ & $\%$ & $\mathbf{N}$ & $\%$ & $\mathbf{N}$ & $\%$ & $\mathbf{N}$ & $\%$ & $\mathbf{N}$ & $\%$ & Paket & Liste \\
\hline $\begin{array}{l}\text { Sosyal ve } \\
\text { Beşerî Bilimler }\end{array}$ & 2.625 & 72 & 3.206 & 69 & 2.853 & 76 & 1.512 & 81 & 7.571 & 74 & $209.206,96$ & $260.263,92$ \\
\hline $\begin{array}{l}\text { Fen Müh. Tek. } \\
\text { Mat. }\end{array}$ & 735 & 20 & 608 & 13 & 338 & 9 & 137 & 7 & 1.083 & 11 & $80.624,64$ & $100.386,36$ \\
\hline $\begin{array}{l}\text { Tip ve Sağlık } \\
\text { Bilimleri }\end{array}$ & 306 & 8 & 815 & 18 & 542 & 15 & 217 & 12 & 1.574 & 15 & $24.116,48$ & $28.780,34$ \\
\hline Toplam & 3.666 & 100 & 4.629 & 100 & 3.733 & 100 & 1.866 & 100 & 10.228 & 100 & 313.948,08 & $389.430,62$ \\
\hline
\end{tabular}

Konuya göre satın alınan e-kitapların sayısı, kullanımı, paket ve liste fiyatı

Paket ve bireysel başlık halinde satın alınan e-kitapların konu alanlarına göre birim kullanım ve ortalama kitap maliyetleri Tablo 11'de gösterilmektedir. Hem paket hem de bireysel alımda en düşük birim kullanım ve ortalama kitap maliyeti tıp ve sağlık bilimlerinde en yüksek ise fen, mühendislik, teknoloji ve matematik konu alanında çıkmıştır. Bu durum üç konu alanı içinde kitap sayısına göre en yüksek ödemenin bu alan için yapıldığını göstermektedir.

Tablo 11

Satın alınan e-kitapların konu alanlarına göre birim kullanım ve ortalama kitap maliyeti

\begin{tabular}{lrrrr} 
& \multicolumn{2}{c}{$\begin{array}{c}\text { Paket halinde satın } \\
\text { alınan }\end{array}$} & \multicolumn{2}{c}{$\begin{array}{c}\text { Bireysel başlık halinde satın } \\
\text { alınan }\end{array}$} \\
\hline Konu alanları & BKM (\$) & OKM (\$) & BKM (\$) & OKM (\$) \\
\hline Sosyal ve Beşerî Bilimler & 27,63 & 79,70 & 34,38 & 99,15 \\
Fen, Mühendislik, Teknoloji, Matematik & 74,45 & 109,69 & 92,69 & 136,58 \\
Tıp ve Sağlık Bilimleri & 15,32 & 78,81 & 18,28 & 94,05 \\
\hline
\end{tabular}

Not: BKM: Birim Kullanım Maliyeti, OKM: Ortalama Kitap Maliyeti

\section{DDA Modeli (Talep Odaklı Să̆lama)}

DDA modelinde e-kitaplar görünür hale geldikten sonra kullanıcı tek oturumda 10 dakika süresince bir başlığı tararsa, bir başlığın 10'dan fazla sayfasını tararsa, bir başlığın herhangi bir bölümünü indirirse, bir başlığın herhangi bir bölümünü başka bir kullanıcıya e-posta ile 
gönderirse, başlığın herhangi bir bölümünün çıktısını alırsa otomatik satın alma gerçekleşmektedir. DDA modeliyle satın alınan e-kitapların kullanım istatistikleri ile paket olarak satın alınan e-kitapların kullanım istatistikleri birbirinden farklı olduğu için paket olarak satın alınan e-kitap kullanımlarının hangi DDA koşuluna karşılık geldiği aşağıda açıklanmıştır:

- Bölüm indirme: Kullanıcı bir başlığın herhangi bir bölümünü indirirse

- Tam indirme: Kullanıcı bir başlığın herhangi bir bölümünü indirirse

- Çevrimiçi görüntüleme: Kullanıcı tek oturumda 10 dakika süresince bir başlığı tararsa veya bir kullanıcı tek oturumda bir başlığın 10'dan fazla sayfasını tararsa

- Yazdırma isteği: Kullanıcı başlığın herhangi bir bölümünün çıktısını alırsa

- E-posta isteği: Kullanıcı bir başlığın herhangi bir bölümünü başka bir kullanıcıya eposta ile gönderirse

- Kaydetme isteği: Kullanıcı bir başlığın herhangi bir bölümünü indirirse (Kullanıcının, sayfayı kaydetmeden önce indirmesi gerektiği için bu koşulun "kaydetme isteğini" sağladığını belirtmek mümkündür.)

- Ayrıntılı kayıt görüntüleme: Bir kullanıcı tek oturumda 10 dakika süresince bir başlığı tararsa veya bir kullanıcı tek oturumda bir başlığın 10'dan fazla sayfasını tararsa

\section{Senaryo 1: DDA Modeli-Otomatik Satın Alma}

DDA koşullarında açıklandığı gibi kullanım istatistiklerinde bir kez kullanım görüldüğünde kitapların tetiklenerek otomatik satın alındığı kabul edilmektedir. Örneğin $A$ kitabı 2016 yılında çevrimiçi görüntülemede bir kez kullanıldıysa kullanıcının tek oturumda 10 dakika süresince bir başlığı taradığı veya tek oturumda bir başlığın 10'dan fazla sayfasını taradı ğ koşulunu sağladığı için otomatik satın almaya girmiştir. $A$ kitabı 2016 yılında otomatik satın alındığı için 2017 yılı DDA uygulamasında bu kitap için herhangi bir işlem yapılmamış ve sadece 2017 yılında görülen kullanım istatistiği birim kullanım maliyetini hesaplamada dikkate alınmıştır.

2016-2018 yılları arasında DDA modeli ile satın alındığı kabul edilen kitapların sayısı, kullanımları ve maliyetleri Tablo 12'de gösterilmektedir. 2016-2018 yılları için DDA modeliyle toplamda 1.489 kitap satın alınmış ve $162.412,74$ \$ ödeme yapılmıştır.

Tablo 12

2016-2018 yılları arasında DDA modeli ile satın alındiğg kabul edilen e-kitapların sayısl, kullanımı ve maliyeti

\begin{tabular}{lrrrrrr}
\hline \multirow{2}{*}{ Satın alma yılı } & \multirow{2}{*}{$\begin{array}{c}\text { Satın alınan } \\
\text { kitap sayısı }\end{array}$} & $\mathbf{2 0 1 6}$ & $\mathbf{2 0 1 7}$ & $\mathbf{2 0 1 8}$ & Toplam & \multirow{2}{*}{ Maliyet } \\
\cline { 3 - 6 } & 783 & 4.629 & 2.105 & 942 & 7.676 & $86.435,74$ \\
2016 & 416 & & 1.628 & 190 & 1.818 & $45.964,88$ \\
2017 & 290 & & & 734 & 734 & $30.012,12$ \\
2018 & $\mathbf{1 . 4 8 9}$ & $\mathbf{4 . 6 2 9}$ & $\mathbf{3 . 7 3 3}$ & $\mathbf{1 . 8 6 6}$ & $\mathbf{1 0 . 2 2 8}$ & $\mathbf{1 6 2 . 4 1 2 , 7 4}$ \\
\hline Toplam & & & & &
\end{tabular}

DDA modelinin birim kullanım ve ortalama kitap maliyeti ise aşağıdaki gibi hesaplanmıştır:

$$
\begin{aligned}
& B K M=M / K \quad \rightarrow \quad B K M=162.412,74 / 10.228 \quad \rightarrow \quad B K M=15,88 \$ \\
& O K M=M / S \rightarrow O K M=162.412,74 / 1.489 \rightarrow O K M=109,07 \$
\end{aligned}
$$


Paket halinde satın alındığında birim kullanım maliyeti 30,69 \$ iken DDA modelinde bu rakam yarı yarıya düşmüş ve sadece kullanıcıların istediği başlıklar satın alınmıştır.

\section{Konu Analizi}

Tablo 13'teki konu alanlarına göre dağılımda 2016-2018 yılları arasında kullanıcılar tarafından tetiklenerek en fazla satın alınan kitap sayısı $(\mathrm{N}=1112, \% 75)$, en yüksek kullanım $(\mathrm{N}=7571$, \%74) ve en yüksek maliyet (115.836,06 \$) sosyal ve beşerî bilimlerde görülmüştür. Satın alınan kitap sayısı arttıkça kullanım artmış ve buna bağlı olarak satın alma maliyetleri yükselmiştir.

Tablo 13

DDA Modeli ile satın alındı̆̆ kabul edilen e-kitapların konuya göre dă̆ılımı, kullanımı ve maliyeti (2016-2018)

\begin{tabular}{|c|c|c|c|c|c|c|c|c|c|c|c|}
\hline \multirow{3}{*}{ Konu } & \multirow{2}{*}{\multicolumn{2}{|c|}{$\begin{array}{c}\text { Satın alınan kitap } \\
\text { sayısı }\end{array}$}} & \multicolumn{8}{|c|}{ Kullanım } & \multirow{3}{*}{$\begin{array}{l}\text { Maliyet } \\
\text { (\$) }\end{array}$} \\
\hline & & & \multicolumn{2}{|c|}{2016} & \multicolumn{2}{|c|}{2017} & \multicolumn{2}{|c|}{2018} & \multicolumn{2}{|c|}{ Toplam } & \\
\hline & $\mathbf{N}$ & $\%$ & $\mathbf{N}$ & $\%$ & $\mathbf{N}$ & $\%$ & $\mathbf{N}$ & $\%$ & $\mathbf{N}$ & $\%$ & \\
\hline Sosyal* & 1.112 & 75 & 3.206 & 69 & 2.853 & 76 & 1.512 & 81 & 7.571 & 74 & $115.836,06$ \\
\hline Fen** & 229 & 15 & 608 & 13 & 338 & 9 & 137 & 7 & 1.083 & 11 & $31.270,85$ \\
\hline T1р*** & 148 & 10 & 815 & 18 & 542 & 15 & 217 & 12 & 1.574 & 15 & $15.305,83$ \\
\hline Toplam & 1.489 & 100 & 4.629 & 100 & 3.733 & 100 & 1.866 & 100 & 10.228 & 100 & $162.412,74$ \\
\hline
\end{tabular}

Not: * Sosyal ve Beşerî Bilimler, **Fen Mühendislik Teknoloji Matematik, ***Tıp ve Sağlık Bilimleri

DDA Modelinin konu alanlarına göre birim kullanım ve ortalama kitap maliyetleri Tablo 14'te gösterilmektedir. En düşük birim kullanım maliyeti tıp ve sağllk bilimlerinde $(9,72$ $\$$ ), en yüksek birim kullanım maliyeti ise fen, mühendislik, teknoloji ve matematik $(28,87 \$)$ konu alanında gerçekleşmiştir. Çünkü tıp ve sağllk bilimleri için harcanan toplam maliyet satın alınan kitap sayısına bağlı olarak diğer alanlardan daha az ancak kullanımı harcanan maliyete göre daha yüksektir.

Tablo 14

DDA Modeli-otomatik satın almanın konu alanlarına göre birim kullanım ve ortalama kitap maliyeti

\begin{tabular}{lrr}
\hline Konu Alanları & BKM (\$) & OKM (\$) \\
\hline Sosyal ve Beşerî Bilimler & 15,30 & 104,17 \\
Fen, Mühendislik, Teknoloji, Matematik & 28,87 & 136,55 \\
Tıp ve Sağlık Bilimleri & 9,72 & 103,42 \\
\hline
\end{tabular}

Not: BKM: Birim Kullanım Maliyeti, OKM: Ortalama Kitap Maliyeti

\section{Senaryo 2: DDA Modeli-Kısa Vadeli Ödünç (STL)}

$\mathrm{Bu}$ modelde bir kullanıcı bölüm indirme, tam indirme, çevrimiçi görüntüleme vb. bir eylemi gerçekleştirdiğinde Bir STL kullanılmakta ve üç STL kullanımından sonraki dördüncü kullanım isteğinde kitap otomatik olarak satın alınmaktadır. Örneğin bir e-kitabın 2016 yılı kullanım istatistiklerinde dört kullanımı varsa hem üç STL kullanıldığı hem de kitabın otomatik satın almaya girdiği anlamına gelmektedir. Kitap üç STL kullanımından sonra otomatik satın almaya girdiği için 2017-2018'de kullanılmış olsa bile ayrıca bir fiyatlandırma yapılmamış sadece kullanımları birim kullanım maliyeti hesaplamasında dikkate alınmıştır. STL kullanımları yıldan yıla birikimli gitmemekte, her bir STL kullanımı ilgili yıl bazında değerlendirilmektedir. 
Tablo 15'te yıllara göre STL kullanımları verilmektedir. Otomatik satın almayı tetikleyen başlıklar en fazla kullanılan başlıklar olmuştur. 2016-2017-2018 y1llarında kullanılan toplam 1.489 başlıktan \%41'i tetiklenerek 596 kitap satın alınmış ve kitapların liste fiyatları üzerinden maliyeti 63.741,20 \$ olarak hesaplanmıştır.

Tablo 15

2016-2018 yılları arası STL kullanımı, otomatik satın alınan kitap sayısı ve maliyeti

\begin{tabular}{|c|c|c|c|c|c|c|}
\hline \multirow[b]{2}{*}{ Yıl } & \multicolumn{4}{|c|}{ Kullanım } & \multirow[b]{2}{*}{$\begin{array}{c}\text { Otomatik satın alınan } \\
\text { kitap sayısı }\end{array}$} & \multirow{2}{*}{$\begin{array}{c}\text { Otomatik satın alma } \\
\text { maliyeti }(\$)\end{array}$} \\
\hline & $1 \mathrm{STL}$ & 2 STL & $3 \mathrm{STL}$ & $\begin{array}{l}\text { Toplam } \\
\text { STL }\end{array}$ & & \\
\hline 2016 & 271 & 216 & 1.212 & 1.699 & 330 & $36.659,81$ \\
\hline 2017 & 224 & 160 & 774 & 1.158 & 206 & $21.572,86$ \\
\hline 2018 & 251 & 138 & 273 & 662 & 60 & $5.508,53$ \\
\hline Toplam & 746 & 514 & 2.259 & 3.519 & 596 & $63.741,20$ \\
\hline
\end{tabular}

Not: STL: Short Term Loan

Derleyici firmada STL maliyeti, kitabın kullanıcının üzerinde kaldığı zaman aralığı dikkate alınarak gün sayısına göre değiştiği için Tablo 16'da gün sayısına göre toplam maliyetler gösterilmektedir. STL maliyetleri sırasıyla toplam maliyetin yaklaşık bir gün için \%47'sine, yedi gün için \%55'ine, 14 gün için \%60'1na, 28 gün için \%64'üne karşılık gelmektedir. DDA modelindeki toplam maliyetler kullanılan STL'nin gün sayısına bağlı olarak artmaktadır. Otomatik satın alınan kitap sayısı $(N=596)$ her hesaplamada sabit kaldığı için değişen STL miktarları birim kullanım maliyetlerini de etkileyerek artmasına sebep olmaktadır. En yüksek birim kullanım maliyeti ise 17,51 \$ ile 28 günlük STL kullanımın da görülmektedir. Tablo 16

Gün sayısına göre STL'li DDA Modeli maliyetleri (2016-2018)

\begin{tabular}{lrrrrr}
\hline STL gün sayısı & STL maliyeti (\$) & OSA maliyeti (\$) & Toplam maliyet $\mathbf{( \$ )}$ & BKM (\$) & OKM (\$) \\
\hline 1 gün & $57.701,23$ & $63.741,20$ & $121.442,43$ & 11,87 & 203,76 \\
7 gün & $76.934,98$ & $63.741,20$ & $140.676,18$ & 13,75 & 236,03 \\
14 gün & $96.168,75$ & $63.741,20$ & $159.909,95$ & 15,63 & 268,30 \\
28 gün & $115.402,52$ & $63.741,20$ & $179.143,72$ & 17,51 & 300,58 \\
\hline
\end{tabular}

Not 1: STL: Short Term Loan, OSA: Otomatik Satın Alım, BKM: Birim Kullanım Maliyeti, OKM: Ortalama Kitap Maliyeti

\section{Konu Analizi}

Tablo 17'de görüldüğü üzere STL'nin uygulanmasıyla en düşük birim kullanım maliyeti tıp ve să̆llk bilimlerinde (yedi gün için 9,14 \$), en yüksek birim kullanım maliyeti ise fen, mühendislik, teknoloji ve matematik (yedi gün için 22,70 \$) konu alanında görülmektedir. Tip ve sağlık bilimlerinde birim kullanım maliyetinin düşük olmasının hem STL hem de otomatik satın alım maliyetlerinin düşük ve kullanımların maliyetlere göre yüksek olmasıyla açıklamak mümkündür. 
Tablo 17

Konu alanlarına göre STL maliyeti, otomatik satın kitap saylst ve birim kullanım maliyeti (2016-2018)

\begin{tabular}{|c|c|c|c|c|c|c|c|}
\hline Konu alanları & $\begin{array}{l}\text { STL } \\
\text { gün } \\
\text { sayısı } \\
\end{array}$ & $\begin{array}{c}\text { Toplam STL } \\
\text { maliyeti } \\
(\$)\end{array}$ & $\begin{array}{c}\text { OSA } \\
\text { sayısı }\end{array}$ & $\begin{array}{c}\text { OSA } \\
\text { maliyeti } \\
(\$)\end{array}$ & $\begin{array}{l}\text { Toplam } \\
\text { kullanım }\end{array}$ & $\begin{array}{c}\text { Toplam } \\
\text { maliyet } \\
(\$)\end{array}$ & $\begin{array}{c}\text { BKM } \\
(\$)\end{array}$ \\
\hline \multirow{4}{*}{ Sosyal * } & 1 & $41.248,40$ & 69 & $46.710,97$ & 7.571 & $87.959,37$ & 11,62 \\
\hline & 7 & $54.997,83$ & & & & $101.708,80$ & 13,43 \\
\hline & 14 & $68.747,31$ & & & & $115.458,28$ & 15,25 \\
\hline & 28 & $82.496,75$ & & & & $129.207,72$ & 17,07 \\
\hline \multirow{4}{*}{ Fen** } & 1 & $10.724,85$ & 79 & $10.285,48$ & 1.083 & $21.010,33$ & 19,40 \\
\hline & 7 & $14.299,82$ & & & & $24.585,30$ & 22,70 \\
\hline & 14 & $17.874,79$ & & & & $28.160,27$ & 26,00 \\
\hline & 28 & $21.449,77$ & & & & $31.735,25$ & 29,30 \\
\hline \multirow{4}{*}{ Tip*** } & 1 & $5.727,98$ & 448 & $6.744,75$ & 1.574 & $12.472,73$ & 7,92 \\
\hline & 7 & $7.637,34$ & & & & $14.382,09$ & 9,14 \\
\hline & 14 & $9.546,65$ & & & & $16.291,40$ & 10,35 \\
\hline & 28 & $11.456,00$ & & & & $18.200,75$ & 11,56 \\
\hline Toplam & & & 596 & $63.741,20$ & 10.228 & & \\
\hline
\end{tabular}

Not 1: STL: Short Term Loan, OSA: Otomatik Satın Alım, BKM: Birim Kullanım Maliyeti

Not 2:* Sosyal ve Beşerî Bilimler, **Fen, Mühendislik, Teknoloji ve Matematik, ***Tıp ve Sağlık Bilimler

Derleyici firmanın sunduğu e-kitap sağlama modelleri arasında en düşük birim kullanım maliyeti STL'li DDA modelinde görülmüştür ${ }^{2}$ (Tablo 18). STL uygulamasıyla kullanıcıların kısa veya orta vadede ihtiyaçları karşılanmakta, kullanımı daha fazla olan başlıklar ise otomatik olarak satın alınmaktadır. Literatür değerlendirmesinde Kent State Üniversitesi’nde (Zhang ve diğerleri, 2015) STL seçeneğini kullanmanın ekonomik olmadığı belirtilmiştir. Çünkü STL'ler ek masrafları ortaya çıkarmakta üstelik STL kullanım süresi arttıkça toplam maliyetler de artış göstermektedir. Ancak bu durum kurumlara göre farklılık gösterebilir. Tablo 18'de görüldüğü üzere STL kullanmak HÜ Kütüphaneleri için daha ekonomik bir seçenek olarak görünmektedir. Ayrıca ön izleme süresi mevcut kullanım istatistiklerinde bulunmadı̆̆ 1 için değerlendirilememiştir. Eğer ön izleme süresi değerlendirilebilseydi STL'li DDA ya da doğrudan otomatik satın almanın yapıldığı DDA modelinde kullanımlar tetiklenmeden önce ihtiyacın karşılanması mümkün olabilecek ve doğal olarak toplam maliyetler daha da aşağı çekilmiş olacaktı. Ancak bu durumda bile Ward ve Richardson'un (2016) çalışmasında da belirtildiği gibi DDA modelleri ile daha uygun maliyetlerle e-kitap sağlandığını söylemek mümkündür.

Tablo 18

Derleyici firma e-kitap sağlama modellerinin birim kullanım ve ortalama kitap maliyeti

\begin{tabular}{lrrrrr}
\hline Sağlama modeli & \multirow{2}{*}{ Satın alınan kitap sayısı } & Erişim & $\begin{array}{c}\text { Toplam maliyet } \\
\mathbf{( \$ )}\end{array}$ & $\begin{array}{c}\text { BKM } \\
\mathbf{( \$ )}\end{array}$ & $\begin{array}{c}\text { OKM } \\
\mathbf{( \$ )}\end{array}$ \\
\hline Satın alma-Paket & 3.666 & Sürekli & $313.948,08$ & 30,69 & 85,64 \\
Satın alma-Bireysel başlık & 3.666 & Sürekli & $389.430,62$ & 38,07 & 106,23 \\
Otomatik satın alma- DDA & 1.489 & Sürekli & $162.412,74$ & 15,88 & 109,07 \\
STL'li DDA (yedi gün) & 596 & Sürekli & $140.676,18$ & 13,75 & 236,03 \\
\hline
\end{tabular}

Not: BKM: Birim Kullanım Maliyeti, OKM: Ortalama Kitap Maliyeti

\footnotetext{
${ }^{2}$ E-kitapların ödünç verilme süresi 7-14 gün arasında değiştiği için STL kullanımında yedi gün süresi esas alınmıştır.
} 
Derleyici firmada en düşük birim kullanım maliyetinin tıp ve sağlık bilimlerinde en yüksek birim kullanım maliyetinin ise bireysel başlık satın alma modelindeki fen mühendislik teknoloji ve matematik konu alanlarında olduğu görülmektedir (Tablo 19). Bireysel başlık halinde yapılan satın alma modelinde hem kitapların fiyatlarının yüksek olması hem de kullanım garantisinin olmaması bu modelde maliyetlerin yüksek çıkmasına neden olmuştur. Tablo 19

Derleyici firma e-kitap sağlama modellerinin konu alanlarına göre birim kullanım maliyeti

\begin{tabular}{lccc}
\hline \multirow{2}{*}{ Sağlama modeli } & \multicolumn{3}{c}{ BKM (\$) } \\
\cline { 2 - 4 } & $\begin{array}{c}\text { Sosyal ve Beşerî } \\
\text { Bilimler }\end{array}$ & $\begin{array}{c}\text { Fen, Mühendislik Teknoloji ve } \\
\text { Matematik }\end{array}$ & $\begin{array}{c}\text { Tip ve Sağlık } \\
\text { Bilimleri }\end{array}$ \\
\hline Satın alma-Paket & 27,63 & 74,45 & 15,32 \\
Satın alma-Bireysel başlık & 34,38 & 92,69 & 18,28 \\
Otomatik Satın DDA & 15,30 & 28,87 & 9,72 \\
STL'li DDA (yedi gün) & 13,43 & 22,70 & 9,14 \\
\hline
\end{tabular}

Not: BKM: Birim Kullanım Maliyeti

\section{Sonuç ve Öneriler}

Yayıncı firmada modeller arasında en düşük birim kullanım maliyeti 1,18€ ile EBA modelinde en yüksek birim kullanım maliyeti 2,04 $€$ ile abonelik modelinde görülmektedir. Dört yıl için değerlendirmesi yapılan abonelik modelinde satın alma fiyatından çok daha fazla bir miktarda ödeme yapılmakta ve bu sürenin sonunda hiçbir kitap için kalıcı erişim hakkı mümkün olmamaktadır. Paket olarak satın alma modelindeki birim kullanım maliyeti $(1,62 €)$ ise EBA modeline yakın çıkarken paketteki kitapların \%44'ünün hiç kullanılmaması ve kullanılan kitapların da yaklaşık üçte birinin ihtiyacın \%80’ini karşılaması bu modeli cazip kılmamaktadır. EBA modelinde satın alınan e-kitapların devam eden yıllardaki (2015-2016-2017) kullanım oranı düşük olsa da sadece kullanılan ve kullanımın da \%70'ini karşılayan kitapların satın alınması sağlanarak garantili ve daha düşük maliyetlerle harcamaların yapılması mümkün olmuştur. E-kitap edinmede tercih edilen sağlama modeli yapılan toplam harcamaların maliyetini etkilemiştir.

Yayıncı firmada disiplinlere göre e-kitap kullanımları farklılık göstermekte ve bu durum konu alanlarında farklı birim kullanım maliyetlerinin ortaya çıkmasına neden olmaktadır. Kullanımı konusunda endişelerin bulunduğu konu alanları için EBA modeli tercih edilmemelidir. Çünkü bu e-kitaplar için EBA modelinin uygulanması çok az kullanılan ya da hiç kullanılmayan e-kitapların koleksiyona katılmasına neden olacaktır. Hem paket olarak satın alma modelinde (\%21) hem de EBA modelinde (\%27) tıp en çok kullanılan alan olmuştur. Hacettepe Üniversitesi Tıp Fakültesinin akademik personel ve öğrenci sayısının fazla olması ile bu disiplinin ihtiyaç duyduğu bilgiyi aramada elektronik kaynaklara olan yatkınlığının kullanımı artırdığını söylemek mümkündür. Disipline göre e-kitap sağlama modellerinin tercihi değişebilir ancak sadece kullanım değil, tedarikçinin şartları ve kurumun mevcut bütçesi de tercihin yapılmasında etkili olacaktır.

Derleyici firmanın sunduğu modeller arasında en düşük birim kullanım maliyeti STL'li DDA modelinde görülmüştür. Üç yıllık dönem için bu modelin uygulanmasıyla kitapların yaklaşık \%59'unun $(N=2.177)$ hiç kullanılmadığı, kullanılan kitapların $(N=1.489)$ sadece \%16'sının $(N=596)$ tetiklenerek satın alındığı ve geriye kalan \%24'ün ( $N=893)$ kullanımının ise tetik eşiğinin altında olduğu ortaya çıkmıştır. Böylece en fazla kullanılan başlıklar otomatik 
satın alınarak STL kullanımı kütüphane için ekonomik bir seçenek haline gelmiştir. Konu alanı analizinde tıp ve sağlık bilimleri diğer alanlar arasında birim kullanım maliyeti en düşük çıkan konu alanı olmuştur. Bu konu alanında yer alan kitapların liste fiyatları diğer konu alanlarına göre daha düşüktür ve bu durum hem kullanılan STL maliyetlerini hem de otomatik satın alım maliyetlerini etkilemiştir. Bununla birlikte kullanımı az olabilecek disiplinler için STL'li DDA modelinin tercih edilmesi ve kitapların liste fiyatlarına bir sınırlandırmanın getirilmesi anlamlı olabilir. Çünkü kullanımlar ne kadar az olursa STL maliyeti azalacak ve kitaplar otomatik satın almaya girmeden kullanıcının ihtiyacı karşılanmış olacaktır.

Ülkemizde bulunan birçok akademik kütüphane paket olarak satın alma, bireysel başlık halinde satın alma ve abonelik yoluyla e-kitap sağlama modellerini kullanmaktadır. Ancak gerçek bir EBA ve DDA modelinin uygulanması ve diğer akademik kurumlardan elde edilen sonuçlarla karşılaştırılması en etkili e-kitap sağlama modelinin belirlenmesinde önemli bir husustur. Farklı e-kitap sağlama modelleriyle hem daha uygun maliyetlerle e-kitap koleksiyonlarının geliştirilmesi hem de kullanıcılara daha iyi bir hizmetin sunulması sağlanabilir. Ancak aynı sağlama modelini tercih etmenin her bir kurum için aynı etkiyi yaratması beklenmemelidir. Bu anlamda yapılan her araştırmada bu makalenin esas aldığı tez çalışmasında da (Yılmaz, 2019) olduğu gibi süreci özetleyen rehberlerin hazırlanması, kütüphaneci ve tedarikçilerin rollerinin belirlenmesi diğer kütüphanelere bu tür araştırmaların nasıl yapılması ve nelere dikkat edilmesi gerektiği konusunda 1şık tutacaktır. 


\section{Kaynakça}

Al, U., Soydal, İ. ve Tonta, Y. (2010). Analysis of e-book use: The case of ebrary. Publishing in the Networked World: Transforming the Nature of Communication: 14th International Conference on Electronic Publishing. 16-18 June 2010, Helsinki, Finland içinde (s. 315-329). Helsinki: Hanken School of Economics.

Anson, C. ve Connell, R. R. (2009). SPEC Kit 313: E-book collections. Washington, DC: Association of Research Libraries.

Armstrong, C. ve Lonsdale, R. (2005). Challenges in managing e-books collections in UK academic libraries. Library Collections, Acquisitions, and Technical Services, 29(1), 33-50. doi: 10.1080/14649055.2005.10766031

Ashcroft, L. (2011). Ebooks in libraries: An overview of the current situation. Library Management, 32(6/7), 398-407. doi: 10.1108/01435121111158547

Bucknell, T. (2012). Buying by the bucketful: A comparative study of e-book acquisition strategies. Insights, 25(1), 51-60. doi: 10.1629/2048-7754.25.1.51

Carrico, S. B., Cataldo, T. T., Botero, C. ve Shelton, T. (2015). What cost and usage data reveals about e-book acquisitions: Ramifications for collection development. Library Resources \& Technical Services, 59(3), 102-111.

Davies, T. (2017). The evolution of an e-book demand-driven acquisition programme at Swinburne University of Technology. Insights, 30(2), 36-43. doi: 10.1629/uksg.354

Doucette, J. ve Lewontin, A. (2012). Selecting e-books. R. Kaplan (Ed.). Building and managing e-book collections: A how-to-do-it manual for librarians içinde (s. 51-74). Chicago: Neal-Schuman.

E-BASS25. (2013, Mart 15). E-book models \& consortial purchasing: Benefits \& challenges. Erişim adresi: http://ebass25.rhul.ac.uk/

Fischer, K. S. (2016). Patron-driven acquisitions: Assessing and sustaining a long-term PDA e-book program. S. M. Ward, R. S. Freeman ve J. M. Nixon (Ed.). Academic e-books publishers, librarians, and users içinde (s. 107-126). West Lafayette: Purdue University Press.

Grigson, A. (2009). Evaluating business models for e-books through usage data analysis: A case study from the University of Westminster. Journal of Electronic Resources Librarianship, 21(1), 6274. doi: 10.1080/19411260902858623

Grigson, A. (2011). An introduction to e-book business models and suppliers. K. Price ve V. Havergal (Ed.). E-books in libraries: A practical guide içinde (s. 19-36). London: Facet Publishing.

Hodges, D., Preston, C. ve Hamilton, M. J. (2010). Patron-initiated collection development: Progress of a paradigm shift. Collection Management, 35(3-4), 208-221. doi: 10.1080/01462679.2010.486968

Johnson, P. (2013). Developing and managing electronic collections: The essentials. Chicago: American Library Association.

Johnson, P. (2014). Fundamentals of collection development and management (3.bs.). Chicago: American Library Association.

Kahn, M. ve Underwood, P.G. (2013). Issues related to the adoption of e-books in academic libraries: A literature review. South African Journal of Libraries and Information Science, 79(2), 10-17. doi: /10.7553/79-2-141

Lalla, N. J. (2012). E-book publishing-The view from the library. R. Kaplan (Ed.). Building and managing e-book collections: A how-to-do-it manual for librarians içinde (s. 23-34). Chicago: Neal-Schuman. 
Maceviciute, E., Borg, M., Kuzminiene, R. ve Konrad, K. (2014). The acquisition of e-books in the libraries of the Swedish Higher Education Institutions. Information Research, 19(2). Erişim adresi: http://www.informationr.net/ir/19-2/paper620.html

Machovec, G. (2013). Consortial ebook licensing for academic libraries. Journal of Library Administration, 53(5-6), 390-399. doi: 10.1080/01930826.2013.876833

McKiel, A. W. (2007). Ebrary's global ebook survey. Erişim adresi: https://robertoigarza.files.wordpress.com/2010/03/rep-ebrary_s-global-ebook-survey-ebrary2007.pdf

Morris, C. ve Sibert, L. (2011). Acquiring e-books. S. Polanka (Ed.). No shelf required: E-books in libraries içinde (s. 95-124). Chicago: American Library Association.

Newman, M. (2010). HighWire press: 2009 librarian ebook survey. Erişim adresi: http://highwire.stanford.edu/PR/HighWireEBookSurvey2010.pdf

Schroeder, R. ve Boughan, R. (2017). Doing more with less: Adoption of a comprehensive e-book acquisition strategy to increase return on investment while containing costs. Library Resources \& Technical Services, 62(1), 28-36. doi: 10.5860/lrts.62n1.28

Schroeder, R., Wright, T. ve Murdoch, R. (2010). Patron driven acquisitions: The future of collection development. Proceedings of the Charleston Library Conference. Erişim adresi: https://docs.lib.purdue.edu/cgi/viewcontent.cgi?article=1122\&context=charleston

Shen, L., Cassidy, E. D., Elmore, E., Griffin, G., Manolovitz, T., Martinez, M. ve Turney, L.M. (2011). Head first into the patron-driven acquisition pool: A comparison of librarian selections versus patron purchases. Journal of Electronic Resources Librarianship, 23(3), 203-218. doi: 10.1080/1941126X.2011.601224

Solomon, D. ve Gray, B. C. (2018, Haziran). Applicability of evidence-based acquisition model to collection development in engineering subjects. 2018 ASEE Annual Conference and Exposition, Salt Lake City, UT. Erişim adresi: https://www.asee.org/public/conferences/106/papers/21450/view

Soules, A. (2009). The shifting landscape of e-books. New Library World, 110(1-2), 7-21. doi: $10.1108 / 03074800910928559$

Tucker, J. C. (2012). Ebook collection analysis: Subject and publisher trends. Collection Building, 31(2), 40-47. doi: 10.1108/01604951211229836

Vasileiou, M., Hartley, R. ve Rowley, J. (2012). Choosing e-books: A perspective from academic libraries. Online Information Review, 36(1), 21-39. doi: 10.1108/14684521211206944

Vasileiou, M., Rowley, J. ve Hartley, R. (2012). The e-book management framework: The management of e-books in academic libraries and its challenges. Library and Information Science Research, 34(4), 282-291. doi: 10.1016/j.lisr.2012.06.005

Ward, S. M. ve Richardson, R. A. (2016). Use and cost analysis of e-books: Patron-driven acquisitions plan vs. librarian-selected titles. S. M. Ward, R. S. Freeman ve J.M. Nixon (Ed.). Academic ebooks publishers, librarians, and users içinde (s. 127-144). West Lafayette: Purdue University Press.

Y1lmaz, D. (2019). E-kitap sağlama modellerinin karşılaş̧tırmalı analizi: Hacettepe Üniversitesi örneği (Yayımlanmamış yüksek lisans tezi). Hacettepe Üniversitesi, Ankara.

Zhang, Y., Downey, K., Urbano, C. ve Klingler, T. (2015). Notes on operations: A scenario analysis of demand- driven acquisition (DDA) of e-books in libraries. Library Resources \& Technical Services, 59(2), 84-93. doi: 10.5860/lrts.59n2.84 


\section{Summary}

With the rapid development of technology and the opportunities it provides, the popularity of e-books in academic library collections has increased. However, the increase, both in the variety and use of e-books, has brought challenges for collection management. Due to both technological developments and economic conditions, the acquisition models offered by publishers and aggregators continue to change the acquisition process and affect budgets. Knowing the advantages and disadvantages of different acquisition models, such as purchasing (as a package, or individual titles), subscribing, leasing, and demand driven acquisition is of great importance in terms of the efficient use of budgets, and the development of effective collection management. Selection of the most efficient and economical model, in order to meet the user's or collection's needs, on the other hand, requires the analysis of e-book usage data.

In this study, which aims to determine how the choice of an acquisition model affects expenditures, actual usage data from Hacettepe University Libraries were evaluated. Acquisition models offered by a publisher and an aggregator were tested, based on the scenarios developed, and cost and subject analyses were carried out. 15,564 e-books provided by the publisher in 2013 to Hacettepe University under the purchase model were assumed to have been purchased in 2014. Usage data from the years 2014 through 2017 were adapted to the EBA (Evidence Based Acquisition) and subscription model, and then cost and subject analyses were performed. In the EBA model, publisher collections are made available for access during the agreed upon period. At the end of that period, e-books are purchased for the prepaid amount. 3,666 e-books provided by the aggregator in 2013 under the purchase model were assumed to have been purchased in 2016. The usage data between the years 2016-2018 were adapted to the DDA (Demand Driven Acquisition) model. In the DDA model, predetermined e-books are uploaded to the discovery system, and purchased by the library when the title is clicked, read, or downloaded a certain number of times. The DDA model uses Short Term Loan (STL). Cost and subject analyses were performed.

While the unit usage cost of e-books was calculated as $1.62 €$, purchased as a package offered by the publisher, the unit usage cost was $1.18 €$ in the EBA model. The fact that $44 \%$ of the books in the package were not used, and that approximately one-third of the books used met $80 \%$ of the needs, proved that the model was not economical. It was observed that expenditures could be made with guaranteed lower costs, if the EBA model was preferred. Among the models offered by the aggregator, the DDA model with STL had the lowest unit usage cost at $\$ 13.75$. It was shown that, if the DDA model had been applied for the three-year period (20162018), approximately $59 \%$ of the books would never have been used. Only $16 \%$ of the books used would have been triggered and purchased, and the remaining $24 \%$ would have fallen below the trigger threshold. So, it was shown that STL usage, through automatically purchasing the most used titles, would have been an economical option for the library. The subject analyses showed that the frequency of using e-books varies according to the discipline, and that unit usage costs change depending on the total cost paid, and the number of uses. It was observed that the EBA model is more suitable for disciplines in which usage is considered to be high, and long-term. For disciplines which are expected to be of low, or short-term use, depending on the list prices of the books, applying the DDA model with STL could be more appropriate. Because, with the use of STL, the needs of the users can be met in a short time, and the least 
used books would not be automatically purchased. Both for the publisher and the aggregator, the choice of acquisition models according to the discipline, the usage, the budget of the library, and the supplier conditions should be taken into account.

More efficient use of library budgets is only possible by analyzing and evaluating usage data in collection development and management. However, the analyses made based on a certain e-book acquisition model should not be expected to have the same effect in all libraries. Consequently, each and every academic library should make their own evaluation of different e-book acquisition models, in order to provide better service, and to use budgets more efficiently. 